\title{
Sectoral Heterogeneity in Nominal Rigidities in Korea: Implications for Monetary Policy*
}

\author{
Seula Kim** Jae Won Lee***
}

This paper documents how the frequency of price changes differs across sectors in Korea and what implications such heterogeneity may have for monetary policy. Under heterogeneity, i) monetary policy has larger and more persistent real effects, ii) stabilizing an alternative (optimal) price index that places disproportionately larger weights on "sticky" sectors rather than the consumer price index is welfare improving, iii) the central bank, targeting such an alternative index, should move nominal interest rates slowly, which may justify "gradualism" in monetary policy, and iv) the condition for equilibrium determinacy is different. The results suggest that the monetary authority must consider how firms' pricing behaviors differ across sectors in the design of monetary policy.

JEL Classification: C51, E13, E31, E32, E44, J20

Keywords: Heterogeneity, Price Stickiness, Multiple Sectors, DSGE Model, Monetary Policy, Economy of Korea

\section{Introduction}

Previous studies have shown that the frequency of firms' price adjustments differs across sectors and that such heterogeneity generally matters for monetary policy in several dimensions. However, whether it matters significantly or may safely be disregarded in practice depends on the exact shape of the cross-sector distribution of the frequency of price adjustments.

In this paper, we use a simple multi-sector New Keynesian framework as a laboratory to explore quantitative implications. We first infer the sectoral frequency

Received: April 16, 2018. Revised: Oct. 16, 2018. Accepted: Jan. 9, 2019.

* Financial support from the Bank of Korea is gratefully acknowledged. We thank the editor and two anonymous referees for their constructive comments.

* First Author, Ph.D. Student, Department of Economics, University of Maryland, 3114 Tydings Hall, 7343 Preinkert Dr., College Park, MD 20742, Email: seulakim@umd.edu

*** Corresponding Author, Assistant Professor, Department of Economics, University of Virginia, College of Arts and Sciences, Monroe Hall, Room 334, 248 McCormick Road, PO Box 400182, Charlottesville, VA 22904, Email: j12rb@virginia.edu 
of price adjustments along with the size of sectors using time series data on sectoral prices and quantities. Given the estimates of the sector-specific measures of price stickiness, this paper addresses four broad sets of questions: What are the effects of an exogenous shift in monetary policy on output and inflation? What measure of inflation should a central bank target? How would nominal interest rates behave differently if the central bank targeted alternative inflation indices? What conditions does an interest rate rule must satisfy to avoid sunspot-driven fluctuations in inflation and output?

These questions are classic issues in the literature on monetary policy. The present paper revisits these questions, allowing for sectoral heterogeneity in nominal rigidities in the economy of Korea.

Our findings are summarized as follows. The degree of price stickiness differs across sectors, which enables monetary policy to have large and persistent effects on the economy. Stabilizing an alternative (optimal) price index that places disproportionately larger weights on "stickier" sectors rather than the consumer price index (CPI) is welfare improving. This preference results in a moderate yet non-negligible welfare gain of 0.18 percent of steady-state consumption. Moreover, the central bank, targeting such an optimal index, adjusts nominal interest rates gradually. This finding may provide another justification for the monetary authority's preference for slow and cautious changes in the policy rate, which is often dubbed "gradualism" in monetary policy. Finally, heterogeneity in price stickiness alters the condition for equilibrium determinacy although not significantly with our estimates.

This paper is written using a broad set of research on macroeconomic implications of heterogeneity in price rigidity. Bils and Klenow (2004) and Nakamura and Steinsson (2008) provide evidence of such heterogeneity using the micro-level price data of the U.S. economy. Carvalho (2006) and Barsky, House, and Kimball (2007) study the effects of monetary policy shocks under heterogeneous price stickiness. Aoki (2001); Benigno (2004); Mankiw and Reis (2003); and Eusepi, Hobijin, and Tambalotti (2012) propose to target a sticky sector's inflation aggressively. Carvalho, Lee, and Park (2020); Carvalho, Dam, and Lee (2020); Boukaez, Cardia, and Ruge-Murcia (2005); and Lee (2016) estimate the sectoral frequency of price changes using the U.S. time-series data. Finally, Carlstrom, Fuerst, and Ghironi (2006) and Lee and Park (2016) investigate the properties of equilibrium determinacy. ${ }^{1}$

The paper is organized as follows. Section 2 works through a structural model on which our quantitative analysis is based in the subsequent sections. Section 3 introduces the sectors we consider and presents sectoral characteristics, including the size and the price-adjustment frequency. Section 4 reports various implications

\footnotetext{
${ }^{1}$ We refer readers to Carvalho and Schwartzman (2006) for more references.
} 
for monetary policy. Section 5 provides concluding remarks with caveats.

\section{The Model}

Our framework is a standard multi-sector New Keynesian model (Woodford, 2003; Benigno, 2004; Carvalho, 2006; Carvalho, Lee, and Park, 2020; Bhattarai, Lee and Park, 2014). ${ }^{2}$ The economy on the unit interval $[0,1]$ is divided into $J$ sectors. Sectors, indexed by $j \in\{1,2, \cdots, J\}$, produce differentiated goods and are characterized by different degrees of price stickiness $\left\{\alpha_{j}\right\}_{j=1}^{J}$. We use $\mathcal{I}_{j}$ and $n_{j}=\operatorname{length}\left(\mathcal{I}_{j}\right)$ to denote the subinterval and the size for sector $j$, respectively. When the degree of price stickiness is identical across sectors (i.e., $\alpha_{j}=\alpha \forall j$ ), the model is reduced to a standard single-sector New Keynesian model.

\subsection{Households}

\subsubsection{Household Problem}

The representative household in sector $j$, that gains utility from consuming composite goods and disutility from working, maximizes the expected lifetime utility:

$$
\mathbb{E}_{0}\left[\sum_{t=0}^{\infty} \beta^{t}\left\{U\left(C_{j, t}\right)-\frac{1}{n_{j}} \int_{\mathcal{I}_{j}} V\left(N_{j, t}(i)\right) d i\right\}\right],
$$

where the period (dis) utility functions have the following functional forms:

$$
U\left(C_{j, t}\right)=\frac{C_{j, t}^{1-\rho}-1}{1-\rho} \text { and } V\left(N_{j, t}(i)\right)=\frac{N_{j, t}^{1+\eta}(i)}{1+\eta}
$$

Parameter $\rho$ is the coefficient of relative risk aversion, $\frac{1}{\eta}$ is the Frisch elasticity of labor supply, $C_{j, t}$ and $N_{j, t}(i)$ denote, respectively, the household's consumption of composite goods and labor supply to firm $i$ in sector $j$ at time $t$.

The household faces the flow budget constraint:

\footnotetext{
${ }^{2}$ The model is a simple extension of a textbook (three-equation) New Keynesian model. It abstracts from many important features, such as capital accumulation, dynamic price indexation, consumption habit formation, incomplete financial markets, sectoral heterogeneity other than price stickiness, and international trade, all of which may potentially affect the quantitative results. Therefore, although our analysis may serve as a useful starting point for a future study that explores the implications of sectoral heterogeneity in Korea for monetary policy, our results should be taken with caution.
} 


$$
P_{t} C_{j, t}+\mathbb{E}_{t}\left[Q_{t, t+1} B_{j, t+1}\right]=B_{j, t}+\frac{1}{n_{j}} \int_{\mathcal{I}_{j}} W_{j, t}(i) N_{j, t}(i) d i+\frac{1}{n_{j}} \int_{\mathcal{I}_{j}} \prod_{j, t}(i) d i-P_{t} T_{t},
$$

where $P_{t}$ is the price of one unit of composite goods (i.e., the CPI). The household's disposable income at time $t$ is given by the sum of labor income earned by supplying labor hours to firms in sector $j, \frac{1}{n_{j}} \int_{\mathcal{I}_{j}} W_{j, t}(i) N_{j, t}(i) d i$, and profit income from the ownership of firms in sector $j, \frac{1}{n_{j}} \int_{\mathcal{I}_{j}} \prod_{j, t}(i) d i$, net of lump-sum taxes, $P_{t} T_{t}$. We assume that a complete set of securities that completely spans all the states of nature is available; $B_{j, t}$ is the nominal payoffs, and $Q_{t, t+1}$ is the nominal stochastic discount factor.

The first-order optimality conditions are standard: $N_{j, t}(i)^{\eta} C_{j, t}^{\rho}=W_{j, t}(i) / P_{t}$ and $R_{t}^{-1}=\beta \mathbb{E}_{t}\left[\left(C_{j, t}^{\rho} / C_{j, t+1}^{\rho}\right)\left(P_{t} / P_{t+1}\right)\right]$, where $\mathbb{E}_{t} Q_{t, t+1}=R_{t}^{-1}$.

\subsubsection{Consumption Aggregates and Price Indices}

Following Obstfeld and Rogoff (1998 and 2000), we assume that composite consumption goods are given by a Cobb-Douglas aggregate of sectoral goods:

$$
C_{j, t} \equiv \prod_{k=1}^{J}\left(\frac{C_{j, k, t}}{n_{k}}\right)^{n_{k}}
$$

where $C_{j, k, t}$ is the sector $j$ representative household's consumption of sector $k$ goods, which in turn is given by a CES aggregate of individual goods produced in that sector:

$$
C_{j, k, t} \equiv\left[\left(\frac{1}{n_{k}}\right)^{\frac{1}{\sigma}} \int_{\mathcal{I}_{k}} C_{j, k, t}(i)^{\frac{\sigma-1}{\sigma}} d i\right]^{\frac{\sigma}{\sigma-1}}
$$

Parameter $\sigma$ measures the elasticity of substitution between goods.

The solution for the standard expenditure minimization problem yields the price indices and the demand functions for sectoral and individual goods. The CPI, $P_{t}$, and the sectoral price index, $P_{j, t}$, are given as

$$
\begin{aligned}
& P_{t}=\prod_{j=1}^{J}\left(P_{j, t}\right)^{n_{j}}, \\
& P_{j, t}=\left[\left(\frac{1}{n_{j}}\right) \int_{\mathcal{I}_{j}} P_{j, t}(i)^{1-\sigma} d i\right]^{\frac{1}{1-\sigma}} .
\end{aligned}
$$


The sector $j$ representative household's demand for sectoral and individual goods are given as

$$
\begin{aligned}
& C_{j, k, t}=n_{k}\left(\frac{P_{k, t}}{P_{t}}\right)^{-1} C_{j, t}, \\
& C_{j, k, t}(i)=\left(\frac{P_{k, t}(i)}{P_{k, t}}\right)^{-\sigma}\left(\frac{P_{k, t}}{P_{t}}\right)^{-1} C_{j, t} .
\end{aligned}
$$

The aggregate consumption for the economy is obtained by taking the sum of consumption of all representative households:

$$
C_{t} \equiv \sum_{j=1}^{J} n_{j} C_{j, t} .
$$

The total demand for sectoral and individual goods then can be written as

$$
\begin{aligned}
& C_{k, t}=n_{k}\left(\frac{P_{k, t}}{P_{t}}\right)^{-1} C_{t}, \\
& C_{k, t}(i)=\left(\frac{P_{k, t}(i)}{P_{k, t}}\right)^{-\sigma}\left(\frac{P_{k, t}}{P_{t}}\right)^{-1} C_{t},
\end{aligned}
$$

where $C_{k, t}=\sum_{j=1}^{J} n_{j} C_{j, k, t}$ and $C_{k, t}(i)=\sum_{j=1}^{J} n_{j} C_{j, k, t}(i)$.

\subsection{Firms}

A monopolistically competitive firm produces a differentiated product using a linear production function:

$$
Y_{j, t}(i)=A_{j, t} N_{j, t}(i)
$$

where $A_{j, t}$ is the level of sector-specific productivity and evolves exogenously as

$$
\log A_{j, t}=\phi_{j}^{A} \log A_{j, t-1}+\varepsilon_{j, t} ; \quad \varepsilon_{j, t} \sim_{i . i . d} N\left(0, \sigma_{j}^{A^{2}}\right) .
$$

Prices are sticky as in Calvo (1983) and Yun (1996). Each producer in sector $j$ resets his or her price with a fixed per-period probability $\left(1-\alpha_{j}\right)$. Therefore, a price-adjusting firm sets its price $P_{j, t}(i)$ to maximize a discounted sum of the current and future expected profits: 


$$
\max _{P_{j, t}(i)} \mathbb{E}_{t} \sum_{k=0}^{\infty}\left(\alpha_{j}^{k} Q_{t, t+k}\right)\left[P_{j, t}(i) Y_{j, t+k}(i)-(1-s) W_{j, t+k}(i) N_{j, t+k}(i)\right],
$$

subject to the demand function for its product:

$$
Y_{j, t}(i)=\left(\frac{P_{j, t}(i)}{P_{j, t}}\right)^{-\sigma}\left(\frac{P_{j, t}}{P_{t}}\right)^{-1} Y_{t}
$$

where $Q_{t, t+k}=\beta^{k}\left(\frac{P_{t}}{P_{t+k}}\right)\left(\frac{C_{j, t}}{C_{j, t+k}}\right)^{\rho}$, obtained from the household intertemporal optimality conditions, is the stochastic discount factor between $t$ and $t+k$. At each time $t$, the government provides each firm with an employment subsidy $s W_{j, t}(i) N_{j, t}(i)$, and the subsidy rate, $s$, is set to cancel out the mark-up charged by a firm over its marginal cost. The demand function is obtained from (1) imposing market-clearing conditions. ${ }^{3}$ The first-order optimality condition is given by

$$
\mathbb{E}_{t} \sum_{k=0}^{\infty}\left(\alpha_{j}^{k} Q_{t, t+k}\right)\left[\frac{P_{j, t}(i)}{P_{j, t+k}}-\frac{W_{j, t+k}(i)}{P_{j, t+k}} \frac{1}{A_{j, t+k}}\right]\left(\frac{P_{j, t}(i)}{P_{j, t+k}}\right)^{-\sigma}\left(\frac{Y_{t+k}^{j}}{n_{j}}\right)=0
$$

Given that firms within a sector that update their prices at the same time choose a common price $P_{j, t}^{*}(i)=P_{j, t}^{*}$, the law of motion for the sectoral price index is given by

$$
P_{j, t}=\left[\alpha_{j} P_{j, t-1}^{1-\sigma}+\left(1-\alpha_{j}\right) P_{j, t}^{* 1-\sigma}\right]^{\frac{1}{1-\sigma}}
$$

The Calvo parameter, $\alpha_{j}$, is sector-specific, which induces heterogeneity in nominal rigidities.

\subsection{Government}

The government collects lump-sum taxes and uses tax revenues to finance its purchases and the total employment subsidy given to firms. The government budget constraint is therefore written as

$$
P_{t} G_{t}+s \sum_{j=1}^{J} \frac{1}{n_{j}} \int_{\mathcal{I}_{j}} W_{j, t}(i) N_{j, t}(i) d i=P_{t} T_{t}
$$

\footnotetext{
${ }^{3}$ For simplicity, the model abstracts from government purchases and investment.
} 
For simplicity, we assume $G_{t}=0$ throughout the paper.

\subsection{Market Clearing Conditions}

We assume that one-period-ahead state-contingent assets have zero net supply. The financial market-clearing condition is

$$
\sum_{j=1}^{J} B_{j, t+1}=0
$$

which should hold for every possible state that may occur at time $t+1$. For each type of product, the quantity demanded must equal the quantity supplied:

$$
C_{k, t}(i)=Y_{k, t}(i), \forall i
$$

which implies that, at the aggregate level, consumption equals output:

$$
\sum_{j=1}^{J} n_{j} C_{j, t}=C_{t}=Y_{t}
$$

Moreover, given that asset markets are complete, one can easily show that

$$
C_{j, t}=C_{t}=Y_{t}, \forall j
$$

with an appropriate initial condition for wealth distribution.

\subsection{Monetary Policy}

To close the model, two types of monetary policy are considered in turns. First, we consider a "strict inflation targeting" in which the central bank sets the growth rate of an aggregate price index to its target level (zero in our model). We assume the central bank commits itself to follow a "targeting rule" of the form:

$$
\pi_{t}^{\text {target }}=\sum_{j=1}^{J} \delta_{j} \pi_{j, t}=0
$$

where $\pi_{j, t} \equiv \log P_{j, t}-\log P_{j, t-1}$ is the growth rate of the sectoral price index (i.e., sectoral inflation) and $\delta_{j}$ is the relative weight with $\sum_{j=1}^{J} \delta_{j}=1$. An important special case arises when $\delta_{j}=n_{j}$. In this case, $\pi_{t}^{\text {target }}$ is simply the CPI inflation 
rate. $^{4}$

The type of inflation targeting mentioned above has good properties (at least in theory), but it is often not the best description of practical monetary policy given that central banks around the world may have policy objectives other than inflation stabilization, such as real activity stabilization and interest rate smoothing. Therefore, in empirical studies, researchers often consider various forms of "interest rate rules" (or Taylor rules). In this paper, we consider a standard Taylor rule in which the central bank adjusts nominal interest rates when the inflation rate and output deviate from their respective target levels.

\subsection{Equilibrium}

Equilibrium is characterized by an allocation of quantities and prices that satisfy the households' optimality conditions and budget constraint, the firms' optimality conditions, the monetary policy rule, and the market-clearing conditions.

We solve the model by log-linearizing the equilibrium conditions around a deterministic steady state. The appendix provides the full set of log-linearized equations for interested readers.

\section{Sectoral Frequency of Price Adjustments}

Previous studies have shown that heterogeneity in price stickiness generally matters for monetary policy in numerous ways, ranging from the size of real effects of monetary policy changes, to the appropriate inflation index that a central bank should target, and to the design of an optimal monetary policy.

However, whether it matters significantly or may safely be neglected in practice depends on the exact shape of the cross-sector distribution of the degree of price stickiness. Therefore, we first estimate the sectoral infrequency of price adjustments $\left\{\alpha_{j}\right\}$, along with the sector size $\left\{n_{j}\right\}$, using the time series data on sectoral prices and quantities.

\subsection{Sectoral Frequency and Size}

For empirical exercises, we map the "model sectors" into the 12 major categories of household consumption. The 12 sectors are the second-level disaggregation of the aggregate consumption and are reported in Table 1.

We take a semi-structural approach to estimate the sectoral frequency of price adjustments. The Calvo pricing scheme implies that the dynamics of sector $j$ 's

\footnotetext{
${ }^{4}$ See Section 4.1 for further details.
} 
price level (Equation [3]) is approximated by

$$
\log P_{j, t}=\alpha_{j} \log P_{j, t-1}+\left(1-\alpha_{j}\right) \log P_{j, t}^{*}
$$

where the optimal reset price $\log P_{j, t}^{*}$ is a weighted average of current and future nominal marginal costs, $m c_{t}$ :

$$
\log P_{j, t}^{*}=\left(1-\alpha_{j} \beta\right) \sum_{k=0}^{\infty}\left(\alpha_{j} \beta\right)^{k} \mathbb{E}_{t}\left[m c_{t+k}\right]
$$

We follow Bils and Klenow (2004) and assume that $m c_{t}$ follows a random walk. ${ }^{5}$ Equation (4) then implies

$$
\pi_{j, t}=\alpha_{j} \pi_{j, t-1}+\varepsilon_{j, t}
$$

where $\pi_{j, t} \equiv \log P_{j, t}-\log P_{j, t-1}$ and $\varepsilon_{j, t}$ is a serially uncorrelated exogenous term. Equation (5) indicates that sectoral inflation is more persistent if firms in that sector change prices less frequently. We take the quarterly data on sectoral price indices from the Bank of Korea and the Korean Statistical Information Service and estimate $\alpha_{j}$ by MLE methods. Given estimated $\alpha_{j}$, we derive the average duration of price spells by $1 /\left(1-\alpha_{j}\right)$. Besides Equation (5), we do not impose other (crossequation) restrictions implied by our structural model. This "semi-structural" approach gives flexibility relative to a fully-structural model and thus serves our purpose well. $^{67}$

Table 1 summarizes the estimation results. The measure of price stickiness differs across sectors. However, the overall magnitude of heterogeneity is not large. According to our estimates, prices of some expenditure categories, such as "restaurants and hotels" and "clothing and footwear," are sticky. Firms that produce those goods and services take approximately 13 and 11 months, respectively, before they adjust their prices. Prices are relatively more flexible in many other sectors, such as "food and non-alcoholic beverages," "alcoholic beverages and tobacco," "transportation," "communication," and "recreation and culture." Moreover, the degree of price stickiness is similar among those sectors. Our estimates indicate that firms change their prices every three to four months on average.

\footnotetext{
${ }^{5}$ We refer the interested readers to Bils and Klenow (2004) for more details.

${ }^{6}$ However, for other questions we address in the paper, a fully structural model is necessary.

${ }^{7}$ A better way to estimate $\alpha_{j}$ is to look at micro-level data directly (with no economic models). The obvious costs of this approach are time and resources. Moreover, microdata on prices usually have measurement errors and are often not publicly available. We leave this interesting endeavor for future research.
} 
We suspect that the lack of significant differences in estimated $\alpha_{j}$ s among some sectors may be because the sectors under consideration are still broad. Some idiosyncrasies that would be observed at a highly disaggregate level are likely to be averaged out through aggregation. Therefore, our quantitative results in the subsequent sections may understate the importance of heterogeneity. ${ }^{8}$

The table also reports the size of the sectors, $\left\{n_{j}\right\}$. In the model, they are equal to the steady-state value of $\frac{P_{j, t} Y_{j, t}}{P_{t} Y_{t}}$. We calibrate the parameters so that they match the average expenditure share of each consumption category over our sample periods, 2003-2016. The stickiest consumption category, "restaurants and hotels," happens to be one of the largest in size, which is approximately 13 percent of the total household consumption expenditure.

[Table 1] Sectoral frequency of price adjustments

\begin{tabular}{llccc}
\hline & CPI expenditure categories & $n_{j}(\%)$ & $\alpha_{j}$ & Duration \\
\hline 1 & Food and non-alcoholic beverages & 14.15 & 0.1943 & 1.24 \\
2 & Alcoholic beverages and tobacco & 1.30 & 0.0435 & 1.05 \\
3 & Clothing and footwear & 6.44 & 0.7234 & 3.62 \\
4 & Housing, water, electricity, and other fuels & 10.13 & 0.6180 & 2.62 \\
5 & Furnishings, household equipment, and routine household & 3.73 & 0.4679 & 1.88 \\
& & & \\
6 & maintenance & 6.36 & 0.4690 & 1.88 \\
7 & Transportation & 12.28 & 0.3613 & 1.57 \\
8 & Communication & 6.41 & 0.0583 & 1.06 \\
9 & Recreation and culture & 5.51 & 0.2497 & 1.33 \\
10 & Education & 11.77 & 0.5578 & 2.26 \\
11 & Restaurants and hotels & 13.27 & 0.7720 & 4.39 \\
12 & Miscellaneous goods and services & 8.65 & 0.4231 & 1.73 \\
\hline
\end{tabular}

\subsection{Other Parameters}

We mostly use the standard values for the remaining parameters (Table 2). We set the time discount factor $\beta$ to 0.99 so that the steady-state annual real interest rate is 4 percent. The risk aversion parameter, $\rho$, and the inverse of Frisch elasticity of labor supply, $\eta$, are set to 1.3 and 1 , respectively. Finally, the withinsector elasticity of substitution, $\sigma$, is set to 6 . We take the values from Bae (2013), who analyzes the economy of Korea by using a DSGE model. ${ }^{9}$

We estimate the $\mathrm{AR}(1)$ process for the sectoral productivity, assuming that the

\footnotetext{
${ }^{8}$ Investigating a lower level disaggregation of consumption data is interesting. We leave that as a (near) future research project.

${ }^{9}$ See Kim (2014) for another paper that uses a DSGE model to study Korea. Ahn and Kim (2008); Kim and Park (2006); and Chung, Jung, and Yang (2007) analyze monetary policy in Korea by using a similar framework.
} 
persistence and volatility parameters have common values across sectors $\left(\phi_{j}^{A}=\phi^{A}\right.$ and $\left.\sigma_{j}^{A}=\sigma^{A}\right) .{ }^{10}$ This assumption is made mainly because disaggregate laborhour data are unavailable for the sectors we consider. This assumption also enables us to focus on the price stickiness heterogeneity in isolation, excluding other sources of heterogeneity. We use the seasonally adjusted quarterly data on real output and total hours worked to obtain labor productivity and then estimate (2). Our estimate of $\phi^{A}$ is 0.34 , which is smaller than conventional values often used in other studies. We repeat the same analysis with larger values for robustness and find that our numerical results are largely unaffected. ${ }^{11}$

[Table 2] Model parameter values

\begin{tabular}{ccl}
\hline$\beta$ & 0.99 & Time discount factor \\
$\rho$ & 1.3 & Risk aversion \\
$\eta$ & 1 & Inverse of Frisch elasticity \\
$\sigma$ & 6 & Within-sector elasticity of substitution \\
$\phi^{A}$ & 0.34 & Persistence of the productivity shocks \\
$\sigma^{A}$ & 0.0138 & Standard deviation of the shock innovation \\
\hline
\end{tabular}

\section{Implications for Monetary Policy}

Given the estimates of $\left\{\alpha_{j}\right\}$, we now use our structural model as a laboratory to explore the implications of heterogeneity in price stickiness for monetary policy in Korea. We address four broad sets of questions.

First, what inflation index should an inflation-targeting central bank stabilize? Will the CPI inflation targeting still be desired under heterogeneity in $\left\{\alpha_{j}\right\}$ ? If not, then how will an alternative (and better) inflation index look like? Second, does the cross-sector heterogeneity amplify real effects of monetary policy? If so, then how much? Third, how does it affect the equilibrium determinacy condition when monetary policy is characterized by an interest rate rule? Fourth, how do the implied nominal interest rates look like if a monetary authority targets an alternative price index inflation (that takes the sectoral heterogeneity into account) instead of the standard CPI inflation? How do they compare to the data?

\footnotetext{
${ }^{10}$ Realized shocks vary across sectors.

${ }^{11}$ For example, see Section $C$ in the Appendix for the results when $\phi^{A}=0.84$ and $\sigma^{A}=0.0084$, the values used in Bae (2013).
} 


\subsection{Implications for Inflation Targeting}

\subsubsection{Measure of Inflation a Central Bank Should Target}

What measure of inflation should a central bank target? This is an important question. The answer depends on the cross-sector distribution of price stickiness summarized by $\left\{\alpha_{j}, n_{j}\right\}$.

To address this question, we consider an inflation-targeting central bank that follows a strict targeting rule of the form:

$$
\pi_{t}^{\text {target }}=\sum_{j=1}^{J} \delta_{j} \pi_{j, t}=0
$$

An important special case is when $\delta_{j}=n_{j}$, in which case, $\pi_{t}^{\text {target }}$ is simply the growth rate of the CPI. Targeting the CPI inflation under homogeneous price stickiness $\left(\alpha_{j}=\alpha\right.$ for all $\left.j\right)$ in our framework is desired as it maximizes the welfare of households.

However, the CPI inflation targeting is generally suboptimal because it overlooks sectoral heterogeneity, thus treating all sectors symmetrically. Given that inflation in sticky sectors generates major welfare losses, placing disproportionately large weights on sticky sectors is welfare improving (Aoki, 2001; Benigno, 2004; Eusepi, Hobijn, and Tambalotti, 2011; Lee and Sung, 2016).

To see this more clearly, we follow the literature and take a second-order approximation of household welfare. The period utility flow of all households in the economy is given by

$$
W_{t} \equiv \sum_{j=1}^{J} n_{j}\left[U\left(C_{j, t}\right)-\frac{1}{n_{j}} \int_{0}^{1} V\left(N_{j, t}(i)\right) d i\right]
$$

whereas the second-order approximation is given as ${ }^{12}$

$$
\frac{W_{t}-\bar{W}}{W_{C} \bar{C}} \approx-\frac{1}{2} L_{t}
$$

where

\footnotetext{
${ }^{12}$ For a variable $X_{t}, \hat{X}_{t}$ denotes the $\log$-deviation from its steady-state value, $\log X_{t}-\log \bar{X}$, and $\tilde{X}_{t}$ denotes the same but under fully flexible prices. Moreover, $\hat{X}_{j, t}^{R} \equiv \hat{X}_{j, t}-\hat{X}_{t}$ denotes the logdeviation of sector $j$ variable $\left(X_{j, t}\right)$ from its aggregate counterpart $\left(X_{t}\right)$, and $\tilde{X}_{j, t}^{R} \equiv \tilde{X}_{j, t}-\tilde{X}_{t}$ denotes the same but under flexible prices.
} 


$$
L_{t}=(\rho+\eta)\left(\hat{Y}_{t}-\tilde{Y}_{t}\right)^{2}+(1-\eta) \sum_{j=1}^{J}\left(\hat{P}_{j, t}^{R}-\tilde{P}_{j, t}^{R}\right)^{2}+(1+\eta \sigma) \sigma \sum_{j=1}^{J} \frac{n_{j} \alpha_{j}}{\left(1-\alpha_{j}\right)\left(1-\alpha_{j} \beta\right)} \pi_{j, t}^{2} .
$$

Disregarding third and higher order terms, a welfare-maximizing central bank minimizes the following loss function:

$$
\mathcal{L}=-\mathbb{E}_{0} \sum_{t=0}^{\infty} \beta^{t}\left(\frac{W_{t}-\bar{W}}{W_{C} \bar{C}}\right)=\frac{1}{2} \mathbb{E}_{0} \sum_{t=0}^{\infty} \beta^{t} L_{t}
$$

The terms in the period loss function $L_{t}$ show that nominal rigidities generate distortions at various levels of aggregation. At the aggregate level, output deviates from the natural level reflected by $\left(\hat{Y}_{t}-\tilde{Y}_{t}\right)$; each sectoral inflation $\pi_{j, t}^{2}$ represents inefficient firm-level price (and production) dispersions within a sector. Moreover, nominal rigidities prevent relative prices from adjusting to allocate resources efficiently across sectors in response to sectoral disturbances in productivity. That is, the relative outputs deviate from their "efficient" levels (that would prevail under flexible prices); thus, the relative price gaps $\left(\hat{P}_{j, t}^{R}-\tilde{P}_{j, t}^{R}\right)$ appear in the loss function.

When the frequency of price adjustments differs across sectors, targeting an inflation index that places a larger weight on stickier sectors is welfare improving over the simple CPI inflation targeting for two reasons. First, resource misallocations within sectors are pronounced in a stickier sector given that a larger fraction of firms do not adjust prices in response to shocks. In the loss function, the coefficients on sectoral inflation are disproportionately large for sticky sectors (i.e., sectors with large $\alpha_{j}$ ). Second, targeting such a (non-symmetric) inflation index allows flexible-sector prices to move even more freely, which enables the relative prices to adjust not only faster but also with a smaller welfare cost. ${ }^{13}$

Given the parameter values, in particular, the cross-sector distribution $\left\{\alpha_{j}, n_{j}\right\}$, the optimal set of weights $\left\{\delta_{j}^{*}\right\}$ that minimizes the loss function can be obtained. By construction, targeting the "optimal price index" (OPI) inflation $\left(\sum_{j=1}^{J} \delta_{j}^{*} \pi_{j, t}\right.$ $=0)$ is welfare improving over the CPI inflation targeting $\left(\sum_{j=1}^{J} n_{j} \pi_{j, t}=0\right)$, except for the homogeneous frequency case $\left(\alpha_{j}=\alpha\right) \cdot{ }^{14}$ Moreover, the OPI inflation targeting almost replicates (unconstrained) optimal monetary policy, which does not have to follow any parametric rule but is hard to implement in reality (Aoki, 2001 and Benigno, 2004).

\footnotetext{
13 This mechanism is because inflation fluctuations in flexible sectors do not result in large welfare losses, as mentioned above.

${ }^{14}$ In this case, $\delta_{j}^{*}=n_{j}$.
} 


\subsubsection{Optimal Price Index for the Economy of Korea}

In this subsection, we obtain numerically the optimal weights $\left\{\delta_{j}^{*}\right\}$ for the 12 consumption categories and see how the weights are related to sectors' characteristics, such as stickiness of prices and size. We then compare the OPI to the CPI to see how the two have been behaving differently over our sample periods.

Table 3 reports the optimal weights along with the size and the price stickiness measure of the sectors. As discussed above, the optimal weights are positively correlated with the Calvo parameters. For example, our estimates indicate that "restaurants and hotels" is the stickiest sector and thus should receive the highest attention by the central bank under the OPI inflation targeting. The sector's weight (31.64 percent) in the OPI is more than doubled from that in the CPI. On the other hand, "alcoholic beverages and tobacco," the most flexible sector, receives the lowest weight ( 0.15 percent), which indicates that the central bank should let this sector's prices move freely.

The optimal weights are also positively correlated with sector sizes. However, the effect of the size on the optimal weights is not as significant as that of price stickiness. The correlation between the optimal weights $\left(\delta_{j}^{*}\right)$ and the Calvo parameters $\left(\alpha_{j}\right)$ is 0.8403 and that between the optimal weights and the sector size $\left(n_{j}\right)$ is 0.5164 . Moreover, as can be inferred from the coefficients in the loss function, the optimal weight increases at an accelerating rate as the degree of price stickiness increases. Figure 1 illustrates the results, which show scatter plots of the optimal weights and sector characteristics. Overall, our analysis suggests that a sector's price stickiness is the most important determinant for the OPI.

[Table 3] Optimal weights

\begin{tabular}{llcccc}
\hline CPI expenditure categories & $n_{j}(\%)$ & $\alpha_{j}$ & $\delta_{j}^{*}(\%)$ & $\mathbb{E} \pi_{j, t}(\%)$ \\
\hline 1 & Food and non-alcoholic beverages & 14.15 & 0.1943 & 3.46 & 1.2 \\
2 & Alcoholic beverages and tobacco & 1.30 & 0.0435 & 0.15 & 1.2 \\
3 & Clothing and footwear & 6.44 & 0.7234 & 15.91 & 0.9 \\
4 & Housing, water, electricity, and other fuels & 10.13 & 0.6180 & 15.90 & 0.9 \\
5 & Furnishings, household equipment, and & 3.73 & 0.4679 & 2.50 & 0.6 \\
& & & & \\
6 & Heutine household maintenance & 6.36 & 0.4690 & 5.78 & 0.8 \\
7 & Transport & 12.28 & 0.3613 & 6.04 & 1 \\
8 & Communication & 6.41 & 0.0583 & 0.47 & -0.3 \\
9 & Recreation and culture & 5.51 & 0.2497 & 1.69 & 0.4 \\
10 & Education & 11.77 & 0.5578 & 11.25 & 1.4 \\
11 Restaurants and hotels & 13.27 & 0.7720 & 31.64 & 1.2 \\
12 Miscellaneous goods and services & 8.65 & 0.4231 & 5.20 & 0.8 \\
\hline & Correlation with optimal weights & 0.5164 & 0.8403 & 1 & \\
\hline
\end{tabular}


[Figure 1] Optimal weights and sector characteristics

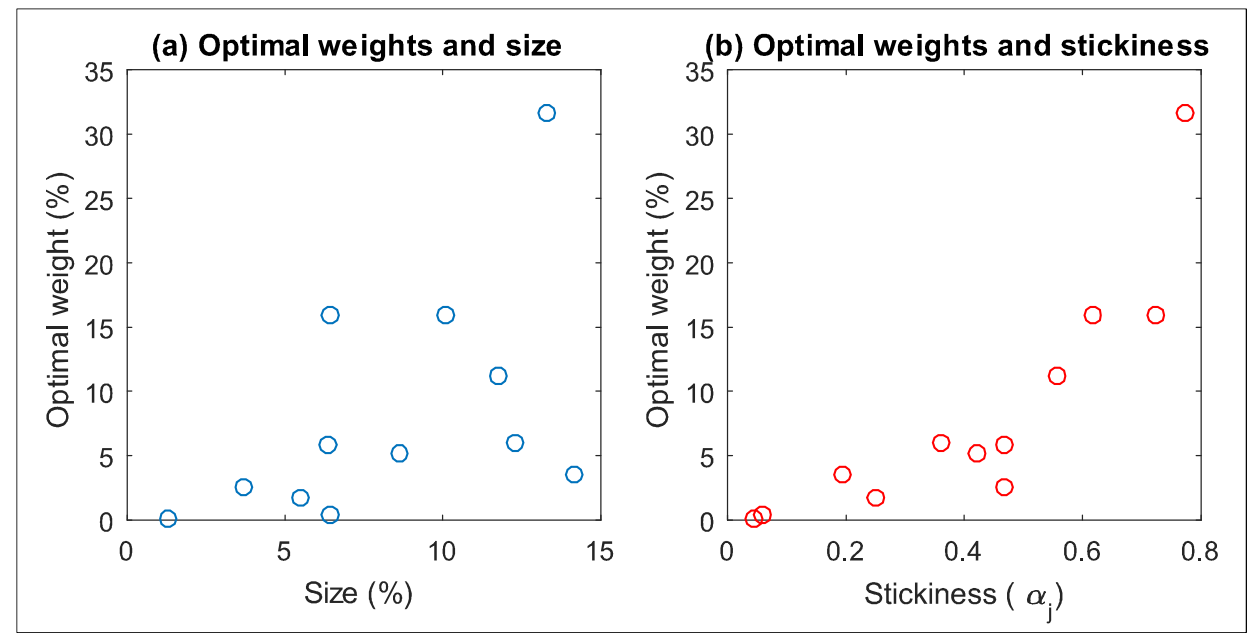

Another sector characteristic that potentially matters for the optimal weights is the average rate of sectoral inflation; they vary across sectors, as shown in the last column on Table 3. It has been reported that relative price distortions tend to be more significant when long-run (average) inflation is higher (Yun, 2005). This finding suggests that the central bank should pay attention to sectors with high average inflation. Our model abstracts from this feature. However, for the sectors we consider, the sectoral difference in the long-run average is relatively small. Therefore, we conjecture that sectoral price stickiness $\left(\alpha_{j}\right)$ continues to be the most important determinant for the optimal weights. ${ }^{15}$ Nevertheless, future research developing a multisector model with different trend inflation across sectors and investigating policy implications in such a model would be of interest. ${ }^{16}$

Figure 2 shows the annualized OPI inflation rate $\left(\pi_{t}^{o p t, y r}\right)$ and the CPI inflation rates $\left(\pi_{t}^{c p i, y r}\right)$ from 2003 to 2016 . The two measures of inflation tend to move together. However, noticeable differences are observed. The OPI inflation is more persistent and less volatile relative to the CPI inflation, as reported in Table 4. ${ }^{17}$ The OPI inflation is slow-moving because disproportionately large weights are placed on slow-moving (sticky) sectors. As shown in the next section, this result has an important implication for the dynamics of nominal interest rates.

\footnotetext{
${ }^{15}$ Moreover, the sectoral long-run inflation rates and the Calvo parameters are positively correlated in our sample. This finding suggests that assigning large weights on stickier sectors generates additional benefits.

${ }^{16}$ In a related note, studying how firms index their prices, which our model does not capture, may also be interesting. Whether firms, when they fail to reoptimize, do not change their prices at all or follow long-run sectoral (or aggregate) inflation may have important policy implications. We leave them as future research.

${ }^{17}$ We also report the statistics for the core-inflation for interested readers.
} 
[Figure 2] OPI inflation versus CPI inflation

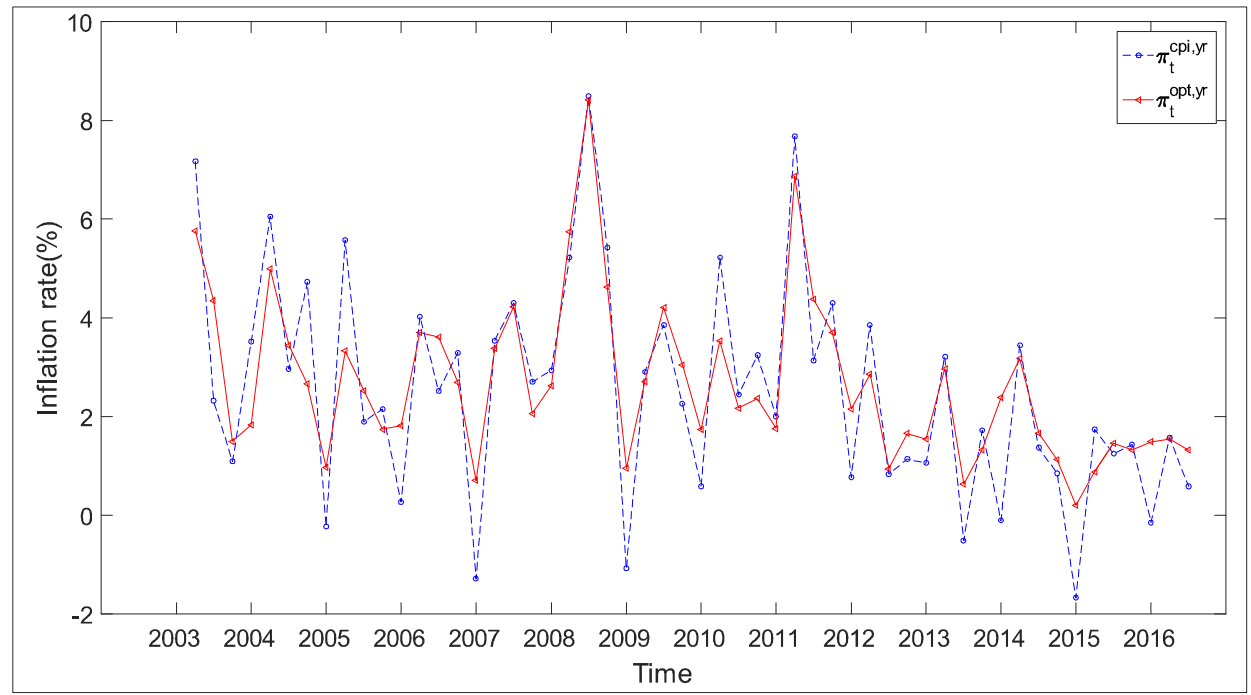

[Table 4] Volatility and persistence of inflation rates

\begin{tabular}{lccc}
\hline Inflation rate index & $\pi^{\text {opt,yr}}$ & $\pi^{\text {cpi,yr }}$ & $\pi^{\text {core,yr }}$ \\
\hline Standard deviation & 1.6419 & 2.2215 & 1.5841 \\
Autocorrelation & 0.3780 & 0.0626 & 0.2756 \\
\hline
\end{tabular}

\subsubsection{Welfare Analysis}

In consideration of small yet non-negligible differences between the two measures of inflation, one may naturally ask the question of whether targeting the OPI inflation results in a significant welfare improvement.

To this end, we use the difference between the (unconditionally) expected welfare losses associated with the two inflation targeting schemes as a measure of welfare improvement:

$$
\left(\mathbb{E}_{\mathcal{L}_{C P I}}-\mathbb{E}_{\mathcal{L}} \mathcal{L}_{O P I}\right) \times 100(\%)=\frac{\mathbb{E} \sum_{t=0}^{\infty} \beta^{t}\left(W_{O P I, t}-W_{C P I, t}\right)}{W_{C} \bar{C}} \times 100(\%) \geq 0
$$

where $W_{O P I, t}$ and $W_{C P I, t}$ denote the period utility flow at time $t$ under the two targeting regimes. The unit of the measure is $W_{C} \bar{C}$.

Our numerical simulation shows that targeting the OPI inflation instead of the CPI inflation yields a welfare gain of 0.18 percent of steady-state consumption. The welfare gain is not huge but should not be dismissed. 


\subsection{Implications for Interest Rate Rules}

Although the (optimal) inflation targeting of the type described above is theoretically appealing, central banks often do not strictly commit to such targeting rules in practice, perhaps to provide themselves with flexibility. Instead, a simple Taylor rule, in which the central bank adjusts its policy instrument in response to changes in inflation and output, is a reasonably good characterization of monetary policy in many countries, including Korea.

Given its empirical relevance, we address three questions associated with the Taylor rules. Would a change in nominal interest rates have a different effect on output and inflation under heterogeneous price stickiness? Would heterogeneity alter the condition for equilibrium determinacy? How would nominal interest rates behave differently if the central bank responded to variations in the OPI inflation rather than the CPI inflation?

\subsubsection{Implications for Real Effects of Monetary Policy}

The effects of monetary policy depend crucially on the cross-sector distribution of price stickiness (Carvalho, 2006; Nakamura and Steinsson, 2008; Lee, 2012). A change in monetary policy has a bigger effect on real output when the frequency of price adjustments differs across sectors owing to strategic complementarity in price settings. The economic mechanism is straightforward. Firms in flexible sectors change their prices by a smaller amount than they would under homogeneous price stickiness because they do not wish to deviate from firms in sticky sectors. Therefore, the aggregate price level adjusts slowly.

Motivated by the theoretical result, we investigate how heterogeneity in $\left\{\alpha_{j}\right\}$ in the previous section affects the central bank's ability to affect real output in Korea. Figure 3 presents the impulse responses of output, inflation, and the price level to an exogenous decrease in the nominal interest rate by 25 basis points. ${ }^{18}$ The response of inflation is more muted under heterogeneous price stickiness; consequently, monetary policy has larger and more persistent effects on output. For example, two years after the shock, output remains above the steady-state by approximately 0.2 percent under heterogeneity. The effect of the shock nearly dies out under homogeneity owing to a fast adjustment of the price level. Panel (b) shows that the inflation rate under homogeneity is greater than that under heterogeneity to some point (6 quarters) and then becomes smaller. This result implies that the price level increases and reaches the new steady-state with a greater speed under homogeneity, which can be seen in Panel (c).

The results suggest that the monetary authority must consider how firms' pricing

\footnotetext{
${ }^{18}$ To produce the impulse responses, we have employed the conventional Taylor rule that will appear in the subsequent subsections.
} 
behaviors differ across sectors when adjusting its policy instrument.

[Figure 3] Impulse responses to an expansionary monetary shock

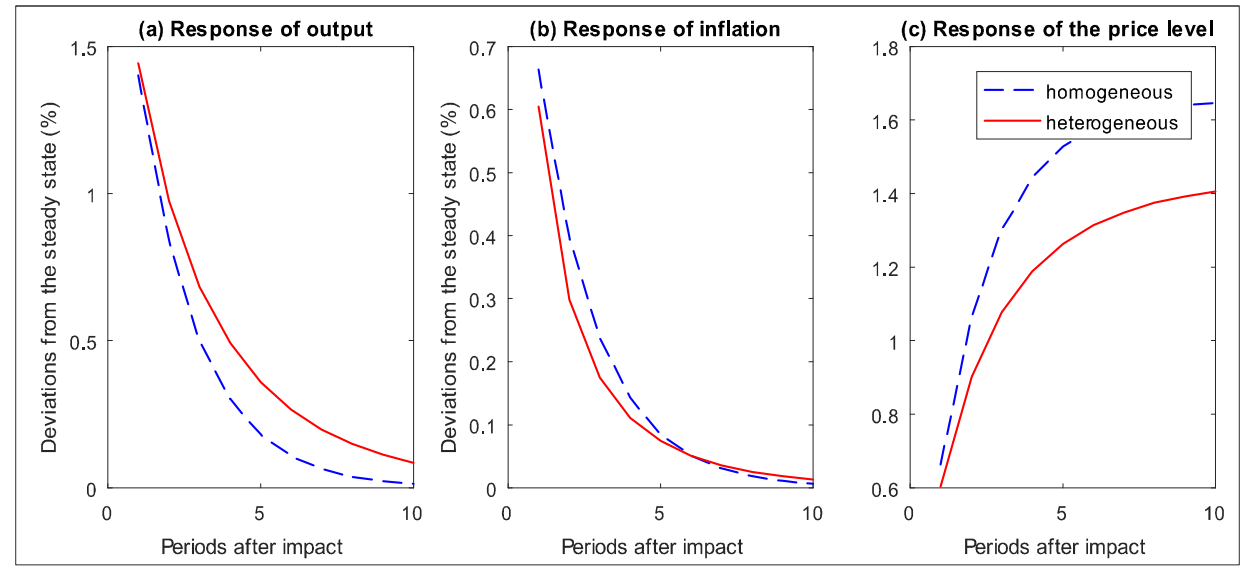

\subsubsection{Implications for Determinacy Condition}

One of the most important guiding principles for practical monetary policy is that the central bank needs to adjust nominal interest rates more than one-for-one to a change in inflation in the long run to ensure price stability. Otherwise, an interest rate rule leads to equilibrium indeterminacy in which nonfundamental factors (often referred to as sunspot shocks) may cause unintended fluctuations in the price level and output.

To fix ideas, we consider a standard Taylor rule with an interest rate smoothing term:

$$
i_{t}=\rho_{i} i_{t-1}+\left(1-\rho_{i}\right)\left\{\bar{i}_{t}+\phi_{\pi}\left(\pi_{t}-\bar{\pi}_{t}\right)+\phi_{y} \tilde{y}_{t}\right\}
$$

where $i_{\mathrm{t}}$ is the (net) nominal interest rate, $\overline{i_{t}}$ is the target (natural) rate of interest, $\bar{\pi}_{t}$ is the target rate of inflation, and $\tilde{y}_{t}$ is the output gap. Parameter $\rho_{i}$ measures the persistence of the interest rate; $\phi_{\pi}$ and $\phi_{y}$ measure how much the interest rate responds to the inflation gap and the output gap, respectively.

Given the Taylor rule, the determinacy condition in conventional New Keynesian models (with $\alpha_{j}=\alpha$ ) is given as

$$
\phi_{\pi}+\phi_{y} \frac{1-\beta}{\kappa}>1
$$

However, the second part, $\phi_{y} \frac{1-\beta}{\kappa}$, is nonsignificant given that $\beta$ is close to one. Thus, under reasonable calibration, the coefficient on inflation $\phi_{\pi}$ has to be 
greater than one to guarantee a unique equilibrium.

The determinacy condition in theory depends on the cross-sector distribution of the frequency of price adjustments (Lee and Park, 2016), because the entire crosssectional distribution of firms affects equilibrium dynamics. This finding implies that the ranges of the policy coefficients $\left(\phi_{\pi}, \phi_{y}\right)$ that guarantee a unique equilibrium may be substantially different from those given in (7).

However, our numerical simulations show that the difference is quantitatively nonsignificant for the sectors we consider here. Figure 4 presents the (in)determinacy regions for homogeneous (solid blue line) and heterogeneous frequency case (dashed red line). For any given value of $\phi_{y}$, smaller values of $\phi_{\pi}$ can guarantee equilibrium determinacy when sectors differ in price stickiness. However, the difference is small for the empirically relevant range of $\phi_{y}$ (less than $0.5)$. We suspect that the small effect resulted from the lack of a sufficient amount of heterogeneity across the sectors under consideration. The result may have been different if we considered more disaggregate sectors.

[Figure 4] Determinacy and indeterminacy regions

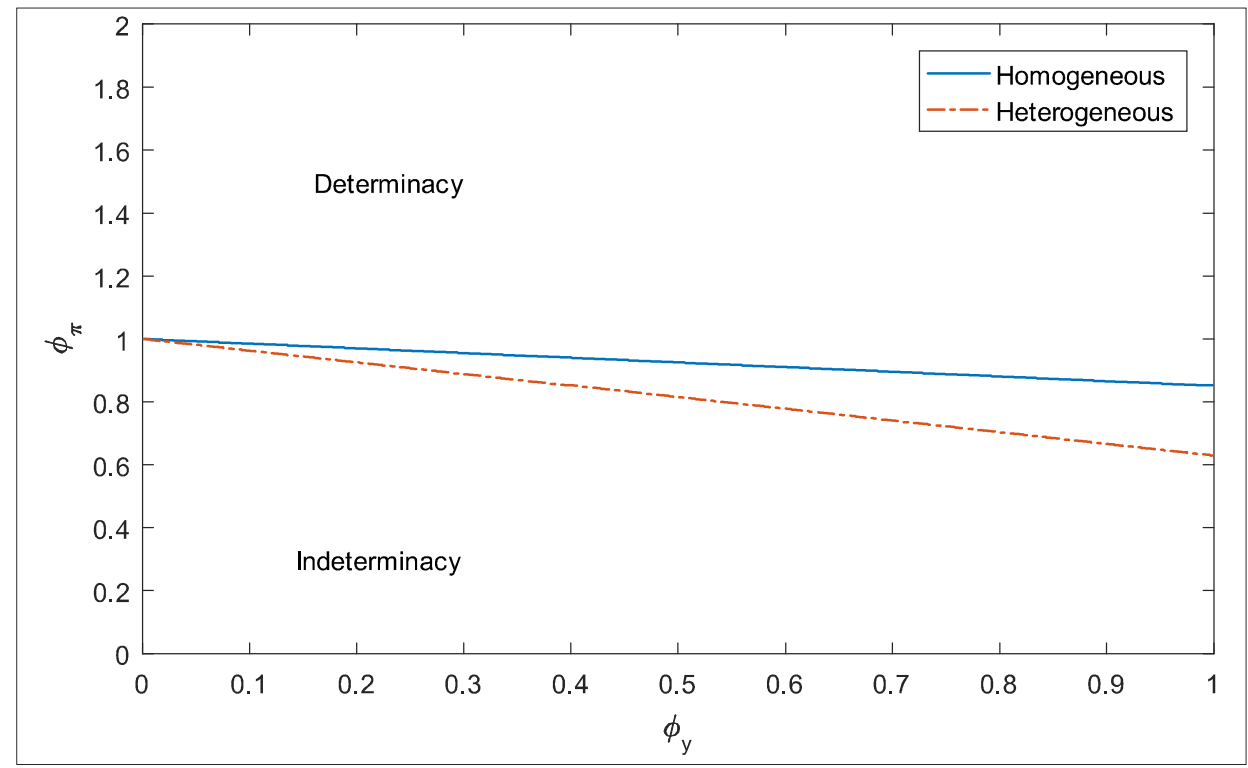

\subsubsection{Implications for Policy Instrument}

Assuming the Taylor rule (6) approximates the monetary policy of the Bank of Korea well, how would the implied nominal interest rate look different if it targeted the OPI instead of the CPI?

To address the question, we parameterize the policy coefficients in (6) following Bae (2013). We set the smoothing parameter $\rho_{i}$ to 0.913 , the coefficient on the inflation gap $\phi_{\pi}$ to 1.66 , and the coefficient on the output gap $\phi_{y}$ to 0.024 . 
Moreover, we use the previous-period uncollateralized call rates (on an annual basis) for $i_{t-1}$, the low-frequency component (obtained from HP filter) of uncollateralized call rates for $\bar{i}_{t}$, the target rate of the annualized inflation announced by the Bank of Korea for $\bar{\pi}_{t}$, and the HP-filtered $\log (\mathrm{GDP})$ as the measure of the output gap $\tilde{y}_{t}$. Finally, we use two alternative (annualized) inflation rates, the CPI inflation $\left(\pi_{t}^{c p i, y r}\right)$ and the OPI inflation $\left(\pi_{t}^{o p t, y r}\right)$, in place of $\pi_{t}$ to compare the implied policy instrument. ${ }^{19}$

Figure 5 shows the interest rates $\left(i_{t}^{c p i, y r}, i_{t}^{o p t, y r}\right)$ implied by the Taylor rule with the two different target inflation rates, as well as the actual time-series data $\left(i_{t}^{\text {data,yr }}\right)$ on the uncollateralized call rate. Several findings are worth mentioning.

First, the simple Taylor rule is a good approximation of the actual monetary policy. The actual policy rate is more persistent and less volatile than the artificial data generated by the rule. This finding may capture the Bank of Korea's preference for smoothing out movements in nominal rates. However, the discrepancy between the data and the model is relatively small.

[Figure 5] Nominal interest rate implied by the Taylor rule

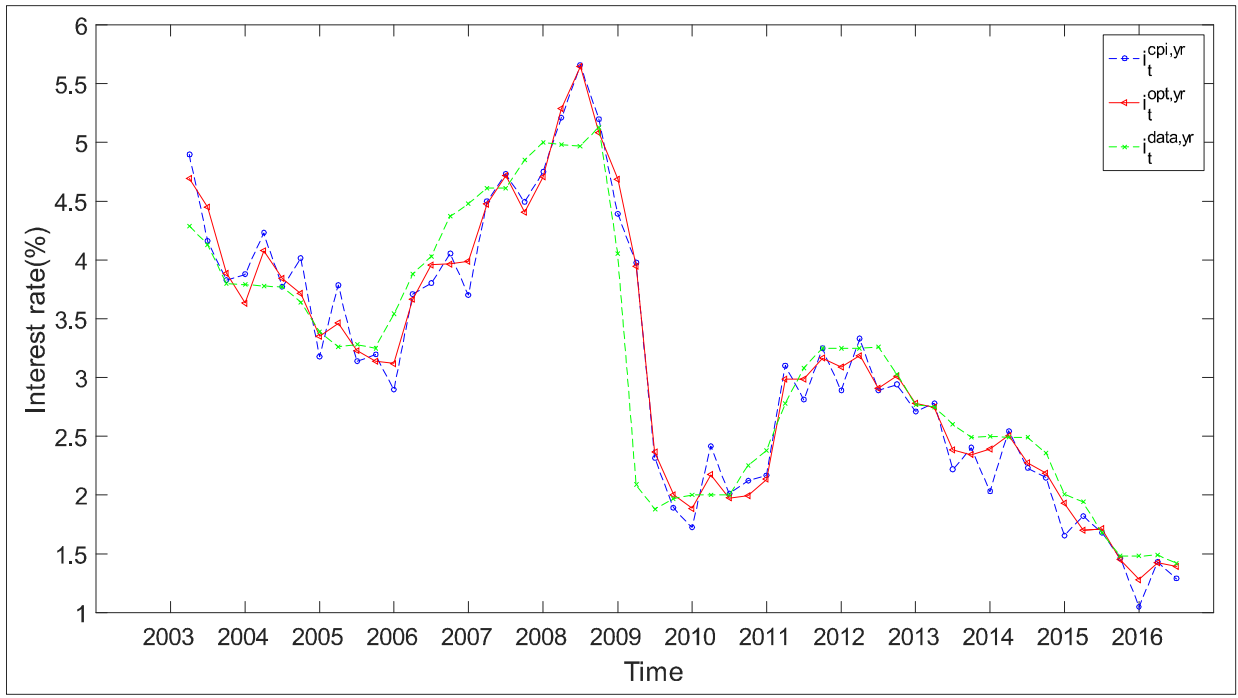

Second, the model-implied interest rates $\left(i_{t}^{c p i, y r}, i_{t}^{\text {opt }, y r}\right)$ are similar to each other. This result implies that the monetary authority not adopting the optimal index would not be a significant mistake. However, in some time periods, non-negligible differences exist between $i_{t}^{c p i, y r}$ and $i_{t}^{o p t, y r}$. For example, the difference was approximately 40 basis points in 2005 and 2014. Overall, $i_{t}^{\text {opt }, y r}$ shows more persistence and less volatility than $i_{t}^{c p i, y r}$ (Table 5) precisely because the OPI

19 The Appendix provides the result also with the core inflation $\left(\pi_{t}^{c o r e, y r}\right)$. 
inflation is more inertial than the CPI inflation (as shown in Figure 2.) This finding naturally leads to our third (and perhaps somewhat surprising) point.

[Table 5] Volatility and persistence of nominal interest rates

\begin{tabular}{lcc}
\hline Interest rates from the Taylor rule & $i_{t}^{\text {opt } y r}$ & $i_{t}^{\text {cpi, }, y r}$ \\
\hline Standard deviation & 1.1105 & 1.1399 \\
Autocorrelation & 0.9015 & 0.8610 \\
\hline
\end{tabular}

Given that $i_{t}^{\text {opt } y r}$ and $i_{t}^{\text {data,yr }}$ are more inertial than $i_{t}^{c p i, y r}$, the actual monetary policy resembles the OPI inflation targeting more than the CPI inflation targeting. Table 6 reports the correlations between the model implied and the actual interest rates. Our analysis suggests that the Bank of Korea (perhaps with no intention) has been acting as if it is stabilizing the optimal index, which is welfare improving. This result becomes more pronounced in the recent periods (2013-2016), in which the bank did not lower the interest rate as much as what the CPI inflation targeting would dictate. Overall, our finding provides another justification for the "gradualism" in monetary policy.

[Table 6] Correlation between the model implied and the actual interest rates

\begin{tabular}{|c|c|c|}
\hline Interest rates from the Taylor rule & $i^{o p t, y r}$ & $i^{c p i, y r}$ \\
\hline Correlation with $i^{\text {data } y r}$ & 0.9475 & 0.9365 \\
\hline
\end{tabular}

\section{Conclusion and Caveats}

This paper documents how the frequency of price changes differs across sectors in Korea and what implications such heterogeneity may have for monetary policy.

Although our findings have potentially important implications for policy and empirical analyses, they should be taken with a grain of salt given that the results are model- and data-specific. We emphasize two shortcomings in our analysis.

First, the structural framework employed in this paper is highly parsimonious. It assumes a closed economy, precluding the role of imported goods and relative prices, such as exchange rates and terms of trade. Clarida et al. (2001) and Gali and Monacelli (2005) have shown that the loss function in a small open economy (under some assumptions) is identical to its closed-economy counterpart, except that the former contains domestic inflation instead of CPI inflation. ${ }^{20}$ In this case, constructing a welfare-relevant OPI requires estimating sectoral price adjustment frequencies based on sectoral prices that exclude the prices of imported goods. The

\footnotetext{
${ }^{20}$ We provide a multisector model of a small open economy in the Appendix (Section E).
} 
resulting estimates of sectoral frequencies based only on domestic goods may or may not be similar to those in Table 1 . Moreover, external shocks that affect terms of trade and exchange rates may play important roles in a small open economy. In our view, this remains an important open question.

Second, we consider only highly aggregated sectors in this paper, assuming away much of heterogeneity that may be observed in more disaggregate sectors. Investigating highly disaggregated consumption data is likely to lead us to an improved understanding of this important topic.

This paper can be a useful starting point for research on sectoral heterogeneity and its macroeconomic implications in the economy of Korea. However, much work remains to be done before we obtain reliable answers. 


\section{Appendix}

\section{A System of Log-linearized Equations}

- For a variable $X_{t}$, we use the following notations:

$$
\begin{aligned}
& X_{t} \equiv \sum_{j=1}^{J} n_{j} X_{j, t}: \text { Aggregate variable } \\
& X_{j, t}^{R} \equiv X_{j, t}-X_{t}: \text { Relative variable } \\
& \hat{X}_{t} \equiv \log X_{t}-\log \bar{X}: \text { Percentage deviation from the steady-state } \\
& \tilde{X}_{t} \equiv \log X_{t}^{N}-\log \bar{X}: \text { Percentage deviation from the steady-state under } \\
& \text { flexible prices }
\end{aligned}
$$

- Household's optimality condition:

$$
\begin{gathered}
\hat{Y}_{t}=\mathbb{E}_{t} \hat{Y}_{t+1}+\frac{1}{\rho}\left(\mathbb{E}_{t} \hat{\pi}_{t+1}-\hat{R}_{t}\right) \\
\eta \hat{N}_{j, t}(i)+\rho \hat{Y}_{t}=\hat{W}_{j, t}(i)-\hat{P}_{t}
\end{gathered}
$$

- Definition of the relative price:

$$
\begin{aligned}
\hat{P}_{j, t}^{R} & =\hat{P}_{j, t}-\hat{P}_{t} \\
\tilde{P}_{j, t}^{R} & =\tilde{P}_{j, t}-\tilde{P}_{t}
\end{aligned}
$$

- Flexible price allocation:

$$
\begin{aligned}
& \tilde{P}_{j, t}^{R}=\frac{(\eta+\rho)}{(\eta+1)} \tilde{Y}_{t}+\hat{A}_{j, t} \\
& \tilde{Y}_{t}=\frac{(\eta+1)}{(\eta+\rho)} \sum_{j=1}^{J} n_{j} \hat{A}_{j, t}
\end{aligned}
$$

- Production function:

$$
\hat{Y}_{j, t}(i)=\hat{A}_{j, t}+\hat{N}_{j, t}(i)
$$

- Demand function: 


$$
\hat{Y}_{j, t}=-\left(\hat{P}_{j, t}-\hat{P}_{t}\right)+\hat{Y}_{t}=-\hat{P}_{j, t}^{R}+\hat{Y}_{t}
$$

- Identities:

$$
\begin{aligned}
& \mathbb{E}_{t} \hat{Q}_{t, t+1}=-\hat{R}_{t} \\
& \pi_{j, t}=\hat{P}_{j, t}-\hat{P}_{j, t-1} \\
& \pi_{t}=\hat{P}_{t}-\hat{P}_{t-1} \\
& \hat{P}_{j, t}^{R}-\hat{P}_{j, t-1}^{R}=\pi_{j, t}-\pi_{t}
\end{aligned}
$$

- New Keynesian Phillips Curve from the firm's optimality condition:

$$
\pi_{j, t}=\frac{\left(1-\alpha_{j}\right)\left(1-\alpha_{j} \beta\right)}{\alpha_{j}(1+\eta \sigma)}\left[-(\eta+1)\left(\hat{P}_{j, t}^{R}-\tilde{P}_{j, t}^{R}\right)+(\eta+\rho)\left(\hat{Y}_{t}-\tilde{Y}_{t}\right)\right]+\beta \mathbb{E}_{t} \pi_{j, t+1}
$$

\section{B Derivation of the Welfare Loss Function}

Following Woodford (2003), we derive the utility-based loss function. We take a second-order Taylor expansion of the utility function $U\left(C_{j, t}\right)$ around the steadystate $\bar{C}$. It is given as

$$
U\left(V_{j, t}\right)=U(\bar{C})+U_{C}\left(C_{j, t}-\bar{C}\right)+\frac{1}{2} U_{C C}\left(C_{j, t}-\bar{C}\right)^{2}+o\left(\|\xi\|^{3}\right)
$$

where $o\left(\|\xi\|^{3}\right)$ denotes all the terms that are of a third or higher order in the deviations of variables from their steady-state values. We also expand $C_{j, t}$ with a second-order Taylor approximation; it is obtained as

$$
C_{j, t}=\bar{C}\left(1+\hat{C}_{j, t}+\frac{1}{2} \hat{C}_{j, t}^{2}\right)+o\left(\|\xi\|^{3}\right)
$$

where $\hat{C}_{j, t}=\log \left(C_{j, t}\right)-\log (\bar{C})$. The deviation of $C_{j, t}$ from its steady-state value $\bar{C}$ can be rewritten as

$$
C_{j, t}-\bar{C}=\bar{C} \hat{C}_{j, t}+\frac{1}{2} \bar{C} \hat{C}_{j, t}^{2}+o\left(\|\xi\|^{3}\right)
$$

Substituting (9), we obtain 


$$
U\left(C_{j, t}\right)=U(\bar{C})+U_{C} \bar{C} \hat{C}_{j, t}+\frac{1}{2} U_{C} \bar{C} \hat{C}_{j, t}^{2}+\frac{1}{2} U_{C C} \bar{C}^{2} \hat{C}_{j, t}^{2}+o\left(\|\xi\|^{3}\right)
$$

Given that $U(\bar{C})$ is independent of monetary policy, we include it in t.i.p., which describes all the terms independent of monetary policy. Then, (10) becomes

$$
U\left(C_{j, t}\right)=U_{C} \bar{C} \hat{C}_{j, t}+\frac{1}{2} U_{C} \bar{C} \hat{C}_{j, t}^{2}+\frac{1}{2} U_{C C} \bar{C}^{2} \hat{C}_{j, t}^{2}+t . i \cdot p .+o\left(\|\xi\|^{3}\right)
$$

which can be reorganized as

$$
U\left(C_{j, t}\right)=U_{C} \bar{C} \hat{C}_{j, t}+\frac{1}{2} U_{C} \bar{C}\left(1+\frac{U_{C C}}{U_{C}} \bar{C}\right) \hat{C}_{j, t}^{2}+t . i \cdot p \cdot+o\left(\|\xi\|^{3}\right) .
$$

Note that $\rho \equiv-\frac{U_{C C} \bar{C}}{U_{C}}$ is defined from the utility function. Thus, we have

$$
U\left(C_{j, t}\right)=U_{C} \bar{C}\left[\hat{C}_{j, t}+\frac{1}{2}(1-\rho) \hat{C}_{j, t}^{2}\right]+t . i \cdot p \cdot+o\left(\|\xi\|^{3}\right) .
$$

Similarly, we take a second-order Taylor expansion of $V\left(N_{j, t}(i)\right)$ around the steady-state $\bar{N}$. We obtain

$$
V\left(N_{j, t}(i)\right)=V(\bar{N})+V_{N}\left(N_{j, t}(i)-\bar{N}\right)+\frac{1}{2} V_{N N}\left(N_{j, t}(i)-\bar{N}\right)^{2}+o\left(\|\xi\|^{3}\right)
$$

The second-order approximation of $N_{j, t}(i)$ is derived as

$$
N_{j, t}(i)=\bar{N}\left(1+\hat{N}_{j, t}(i)+\frac{1}{2} \hat{N}_{j, t}(i)^{2}\right)+o\left(\|\xi\|^{3}\right)
$$

The deviation of $N_{j, t}(i)$ from its steady-state value $\bar{N}$ is written as

$$
N_{j, t}(i)-\bar{N}=\bar{N} \hat{N}_{j, t}(i)+\frac{1}{2} \bar{N} \hat{N}_{j, t}(i)^{2}+o\left(\|\xi\|^{3}\right)
$$

By substituting (15) into (13), we obtain

$$
V\left(N_{j, t}(i)\right)=V(\bar{N})+V_{N}\left(\bar{N} \hat{N}_{j, t}(i)+\frac{1}{2} \bar{N} \hat{N}_{j, t}(i)^{2}\right)
$$




$$
+\frac{1}{2} V_{N N}\left(\bar{N} \hat{N}_{j, t}(i)+\frac{1}{2} \bar{N} \hat{N}_{j, t}(i)^{2}\right)^{2}+o\left(\|\xi\|^{3}\right) .
$$

Using the definition of $o\left(\|\xi\|^{3}\right)$ and t.i.p., we obtain

$$
V\left(N_{j, t}(i)\right)=V_{N} \bar{N} \hat{N}_{j, t}(i)+\frac{1}{2} V_{N} \bar{N} \hat{N}_{j, t}(i)^{2}+\frac{1}{2} V_{N N} \bar{N}^{2} \hat{N}_{j, t}(i)^{2}+t . i . p .+o\left(\|\xi\|^{3}\right),
$$

which can be rewritten as

$$
V\left(N_{j, t}(i)\right)=V_{N} \bar{N}_{N_{j, t}}(i)+\frac{1}{2} V_{N} \bar{N}\left(1+\frac{V_{N N}}{V_{N}} \bar{N}\right) \hat{N}_{j, t}(i)^{2}+t . i . p .+o\left(\|\xi\|^{3}\right) .
$$

Given that $\eta \equiv \frac{V_{N N} \bar{N}}{V_{N}}$, it becomes

$$
V\left(N_{j, t}(i)\right)=V_{N} \bar{N}\left[\hat{N}_{j, t}(i)+\frac{1}{2}(1+\eta) \hat{N}_{j, t}(i)^{2}\right]+t . i \cdot p .+o\left(\|\xi\|^{3}\right) .
$$

From the production function, we obtain

$$
\hat{Y}_{j, t}(i)=\hat{A}_{j, t}+\hat{N}_{j, t}(i)
$$

which derives

$$
\hat{N}_{j, t}(i)=\hat{Y}_{j, t}(i)-\hat{A}_{j, t}
$$

Substituting (18) into (16), we have

$$
V\left(N_{j, t}(i)\right)=V_{N} \bar{N}\left[\left(\hat{Y}_{j, t}(i)-\hat{A}_{j, t}\right)+\frac{1}{2}(1+\eta)\left(\hat{Y}_{j, t}(i)-\hat{A}_{j, t}\right)^{2}\right]+t . i \cdot p .+o\left(\|\xi\|^{3}\right),
$$

which can be rewritten as

$$
V\left(N_{j, t}(i)\right)=V_{N} \bar{N}\left[\hat{Y}_{j, t}(i)+(1+\eta)\left(\frac{1}{2} \hat{Y}_{j, t}(i)^{2}-\hat{A}_{j, t} \hat{Y}_{j, t}(i)\right)\right]+t . i \cdot p \cdot+o\left(\|\xi\|^{3}\right) .
$$

By integrating (20) over the range of $\mathcal{I}_{j}$, we derive 


$$
\begin{aligned}
\frac{1}{n_{j}} \int_{\mathcal{I}_{j}} V\left(N_{j, t}(i)\right) d i= & V_{N} \bar{N}\left\{\mathbb{E}\left(\hat{Y}_{j, t}(i)\right)+\frac{1}{2}(1+\eta) \mathbb{E}\left(\hat{Y}_{j, t}(i)^{2}\right)-(1+\eta) \hat{A}_{j, t} \mathbb{E}_{(}\left(\hat{Y}_{j, t}(i)^{2}\right)\right\} \\
& + \text { t.i.p. }+o\left(\|\xi\|^{3}\right) .
\end{aligned}
$$

This equation implies that

$$
\begin{aligned}
& \frac{1}{n_{j}} \int_{\mathcal{I}_{j}} V\left(N_{j, t}(i)\right) d i \\
& \quad=V_{N} \bar{N}\left\{\mathbb{E}\left(\hat{Y}_{j, t}(i)\right)+\frac{1}{2}(1+\eta) \operatorname{Var}\left(\hat{Y}_{j, t}(i)^{2}\right)+\frac{1}{2}(1+\eta) \mathbb{E}\left(\hat{Y}_{j, t}(i)\right)^{2}-(1+\eta) \hat{A}_{j, t} \mathbb{E}\left(\hat{Y}_{j, t}^{2}\right)\right\} \\
& \quad+\text { t.i.p. }+o\left(\|\xi\|^{3}\right) .
\end{aligned}
$$

We take a second-order Taylor expansion of the aggregated obtaining

$$
\hat{Y}_{j, t}=\mathbb{E}\left(\hat{Y}_{j, t}(i)\right)+\frac{1}{2}\left(\frac{\sigma-1}{\sigma}\right) \operatorname{Var}\left(\hat{Y}_{j, t}(i)\right)+o\left(\|\xi\|^{3}\right) .
$$

It implies

$$
\mathbb{E}\left(\hat{Y}_{j, t}(i)\right)=\hat{Y}_{j, t}-\frac{1}{2}\left(\frac{\sigma-1}{\sigma}\right) \operatorname{Var}\left(\hat{Y}_{j, t}(i)\right)+o\left(\|\xi\|^{3}\right)
$$

and

$$
\mathbb{E}\left(\hat{Y}_{j, i}(i)\right)^{2}=\hat{Y}_{j, t}^{2}+o\left(\|\xi\|^{3}\right)
$$

By substituting (23) and (24) into (22), we derive

$$
\begin{array}{rl}
\frac{1}{n_{j}} \int_{\mathcal{I}_{j}} & V\left(N_{j, t}(i)\right) d i \\
\quad & V_{N} \bar{N}\left\{\hat{Y}_{j, t}+\frac{1}{2}(1+\eta) \hat{Y}_{j, t}^{2}-(1+\eta) \hat{A}_{j, t} \hat{Y}_{j, t}+\frac{1}{2}\left(\eta+\frac{1}{\sigma}\right) \operatorname{Var}\left(\hat{Y}_{j, t}(i)\right)\right\} \\
& + \text { t.i.p. }+o\left(\|\xi\|^{3}\right) .
\end{array}
$$

We have

$$
\bar{N}=\frac{\bar{Y}}{\bar{A}_{j}}=\bar{Y}
$$


From the household's intra-temporal optimality condition. We also have

$$
-\frac{V_{N}}{U_{C}}=\frac{\bar{W}}{\bar{P}}=\bar{A}_{j}=1 .
$$

Thus, this equation implies

$$
-V_{N}=U_{C} \Rightarrow-V_{N} \bar{N}=U_{C} \bar{Y}=U_{C} \bar{C}
$$

Combining these together, household $j$ 's utility function is given as

$$
\begin{aligned}
w_{t}^{j} & =U\left(C_{j, t}\right)-\frac{1}{n_{j}} \int_{\mathcal{I}_{j}} V\left(N_{j, t}(i)\right) d i=U_{C} \bar{C}\left[\hat{C}_{j, t}+\frac{1}{2}(1-\rho) \hat{C}_{j, t}^{2}\right] \\
& -U_{C} \bar{C}\left[\hat{Y}_{j, t}+\frac{1}{2}(1+\eta) \hat{Y}_{j, t}^{2}-(1+\eta) \hat{A}_{j, t} \hat{Y}_{j, t}+\frac{1}{2}\left(\eta+\frac{1}{\sigma}\right) \operatorname{Var}\left(\hat{Y}_{j, t}(i)\right)\right] \\
& + \text { t.i.p. }+o\left(\|\xi\|^{3}\right) .
\end{aligned}
$$

It is then rearranged as

$$
\begin{aligned}
w_{t}^{j} & =U_{C} \bar{C}\left[\hat{C}_{j, t}+\frac{1}{2}(1-\rho) \hat{C}_{j, t}^{2}-\hat{Y}_{j, t}-\frac{1}{2}(1+\eta) \hat{Y}_{j, t}^{2}+(1+\eta) \hat{A}_{j, t} \hat{Y}_{j, t}\right. \\
& \left.-\frac{1}{2}\left(\eta+\frac{1}{\sigma}\right) \operatorname{Var}\left(\hat{Y}_{j, t}(i)\right)\right]+t . i \cdot p \cdot+o\left(\|\xi\|^{3}\right) .
\end{aligned}
$$

From (25), the weighted sum of the utility is

$$
\begin{aligned}
& \sum_{j=1}^{J} n_{j} w_{t}^{j}=\sum_{j=1}^{J}\left[n_{j} U\left(C_{j, t}\right)-\int_{0}^{1} V\left(N_{j, t}(i)\right) d i\right] \\
& =U_{C} \bar{C}\left[\begin{array}{l}
\sum_{j=1}^{J} n_{j} \hat{C}_{j, t}+\frac{1}{2}(1-\rho) \sum_{j=1}^{J} n_{j} \hat{C}_{j, t}^{2}-\sum_{j=1}^{J} n_{j} \hat{Y}_{j, t}-\frac{1}{2}(1+\eta) \sum_{j=1}^{J} n_{j} \hat{Y}_{j, t}^{2} \\
(1+\eta) \sum_{j=1}^{J} n_{j} \hat{A}_{j, t} \hat{Y}_{j, t}-\frac{1}{2}\left(\eta+\frac{1}{\sigma}\right) \sum_{j=1}^{J} n_{j} \operatorname{Var}\left(\hat{Y}_{j, t}(i)\right)
\end{array}\right] \\
& + \text { t.i.p. }+o\left(\|\xi\|^{3}\right) .
\end{aligned}
$$

The resource constraint is given as

$$
Y_{t}=\sum_{j=1}^{J} n_{j} C_{j, t},
$$


which implies

$$
\hat{Y}_{t}=\sum_{j=1}^{J} n_{j} \hat{C}_{j, t} .
$$

From the sectoral goods demand function, we also have

$$
\hat{Y}_{j, t}=-\hat{P}_{j, t}^{R}+\hat{Y}_{t}
$$

from which we obtain

$$
\begin{aligned}
& \sum_{j=1}^{J} n_{j} \hat{Y}_{j, t}=\hat{Y}_{t} \quad \begin{array}{l}
\text { and } \\
\sum_{j=1}^{J} n_{j} \hat{Y}_{j, t}^{2}=\sum_{j=1}^{J} n_{j}\left(\hat{P}_{j, t}^{R}\right)^{2}+\left(\hat{Y}_{t}\right)^{2},
\end{array}
\end{aligned}
$$

given that $\sum_{j=1}^{J} n_{j} \hat{P}_{j, t}^{R}=\sum_{j=1}^{J} n_{j}\left(\hat{P}_{j, t}-\hat{P}_{t}\right)=0$.

From the flexible allocation, we obtain

$$
\hat{A}_{j, t}=-\tilde{P}_{j, t}^{R}+\left(\frac{\eta+\rho}{\eta+1}\right) \tilde{Y}_{t} .
$$

It is rewritten as

$$
(1+\eta) \hat{A}_{j, t}=-(1+\eta) \tilde{P}_{j, t}^{R}+(\eta+\rho) \tilde{Y}_{t}
$$

Using (27), (28), (29), and (30) into (26), we have

$$
\begin{aligned}
& \sum_{j=1}^{J} n_{j} w_{t}^{j}=U_{C} \bar{C}\left[\begin{array}{l}
\hat{Y}_{t}+\frac{1}{2}(1-\rho)\left(\hat{Y}_{t}\right)^{2}-\hat{Y}_{t}-\frac{1}{2}(1+\eta)\left\{\sum_{j=1}^{J} n_{j}\left(\hat{P}_{j, t}^{R}\right)^{2}+\left(\hat{Y}_{t}\right)^{2}\right\} \\
+\sum_{j=1}^{J} n_{j}\left\{-(1+\eta) \tilde{P}_{j, t}^{R}+(\eta+\rho) \tilde{Y}_{t}\right\}\left\{-\hat{P}_{j, t}^{R}+\hat{Y}_{t}\right\} \\
-\frac{1}{2}\left(\eta+\frac{1}{\sigma}\right) \sum_{j=1}^{J} n_{j} \operatorname{Var}\left(\hat{Y}_{j, t}(i)\right)
\end{array}\right] \\
& + \text { t.i.p. }+o\left(\|\xi\|^{3}\right) \\
& =U_{C} \bar{C}\left[\begin{array}{l}
-\frac{1}{2}(\rho+\eta)\left(\hat{Y}_{t}\right)^{2}-\frac{1}{2}(1+\eta) \sum_{j=1}^{J} n_{j}\left(\hat{P}_{j, t}^{R}\right)^{2}+(1+\eta) \sum_{j=1}^{J} n_{j} \tilde{P}_{j, t}^{R} \hat{P}_{j, t}^{R} \\
+(\rho+\eta) \tilde{Y}_{t} \hat{Y}_{t}-\frac{1}{2}\left(\eta+\frac{1}{\sigma}\right) \sum_{j=1}^{J} n_{j} \operatorname{Var}\left(\hat{Y}_{j, t}(i)\right)
\end{array}\right] \\
& + \text { t.i.p. }+o\left(\|\xi\|^{3}\right)
\end{aligned}
$$




$$
\begin{aligned}
& =U_{C} \bar{C}\left[\begin{array}{l}
-\frac{1}{2}(\rho+\eta)\left\{\left(\hat{Y}_{t}\right)^{2}-2 \tilde{Y}_{t} \hat{Y}_{t}+\left(\tilde{Y}_{t}\right)^{2}-\left(\tilde{Y}_{t}\right)^{2}\right\} \\
-\frac{1}{2}(1+\eta) \sum_{j=1}^{J} n_{j}\left\{\left(\hat{P}_{j, t}^{R}\right)^{2}-2 \hat{P}_{j, t}^{R} \tilde{P}_{j, t}^{R}+\left(\tilde{P}_{j, t}^{R}\right)^{2}-\left(\tilde{P}_{j, t}^{R}\right)^{2}\right\} \\
-\frac{1}{2}\left(\eta+\frac{1}{\sigma}\right) \sum_{j=1}^{J} n_{j} \operatorname{Var}\left(\hat{Y}_{j, t}(i)\right)
\end{array}\right] \\
& + \text { t.i.p. }+o\left(\|\xi\|^{3}\right) .
\end{aligned}
$$

Given that $\left(\tilde{Y}_{t}^{W}\right)^{2}$ and $\left(\tilde{P}_{j, t}^{R}\right)^{2}$ belong to t.i.p., we can rewrite (31) as

$$
\begin{aligned}
\sum_{j=1}^{J} n_{j} w_{t}^{j} & =-\frac{1}{2} U_{C} \bar{C}\left[\begin{array}{l}
(\rho+\eta)\left(\hat{Y}_{t}-\tilde{Y}_{t}\right)^{2}+(1+\eta) \sum_{j=1}^{J} n_{j}\left(\hat{P}_{j, t}^{R}-\tilde{P}_{j, t}^{R}\right)^{2} \\
+\left(\eta+\frac{1}{\sigma}\right) \sum_{j=1}^{J} n_{j} \operatorname{Var}\left(\hat{Y}_{j, t}(i)\right)
\end{array}\right] \\
& + \text { t.i.p. }+o\left(\|\xi\|^{3}\right) .
\end{aligned}
$$

The demand for individual goods is given as

$$
Y_{j, t}(i)=\left(\frac{P_{j, t}(i)}{P_{j, t}}\right)^{-\sigma}\left(\frac{P_{j, t}}{P_{t}}\right)^{-1} Y_{t}
$$

By log-linearization, it becomes

$$
\hat{Y}_{j, t}(i)=-\sigma\left(\hat{P}_{j, t}(i)-\hat{P}_{j, t}\right)-\left(\hat{P}_{j, t}-\hat{P}_{t}\right)-\hat{Y}_{t}
$$

We have

$$
\operatorname{Var}\left(\hat{Y}_{j, t}(i)\right)=\sigma^{2} \operatorname{Var}\left(\hat{P}_{j, t}(i)\right)
$$

where $\operatorname{Var}\left(\hat{P}_{j, t}(i)\right)$ describes price dispersion within a sector. Defining $\bar{P}_{t} \equiv \mathbb{E}_{i}$ $\left\{\log \left(P_{j, t}(i)\right)\right\}$, we obtain

$$
\begin{aligned}
& \operatorname{Var}\left(\hat{P}_{j, t}(i)\right)=\operatorname{Var}\left(\log \left(P_{j, t}(i)\right)-\bar{P}_{t-1}\right) \\
&= \mathbb{E}\left(\left(\log \left(P_{j, t}(i)\right)-\bar{P}_{t-1}\right)^{2}\right)-\mathbb{E}\left(\log \left(P_{j, t}(i)\right)-\bar{P}_{t-1}\right)^{2} \\
&= {\left[\alpha_{j} \mathbb{E}\left(\left(\log \left(P_{j, t-1}(i)\right)-\bar{P}_{t-1}\right)^{2}\right)+\left(1-\alpha_{j}\right)\left(\log \left(\tilde{P}_{j, t}(i)\right)-\bar{P}_{t-1}\right)^{2}\right] } \\
& \quad-\mathbb{E}\left(\log \left(P_{j, t}(i)\right)-\bar{P}_{t-1}\right)^{2} \\
&= {\left[\alpha_{j} \operatorname{Var}\left(P_{j, t-1}(i)\right)+\left(1-\alpha_{j}\right)\left(\log \left(\tilde{P}_{j, t}(i)\right)-\bar{P}_{t-1}\right)^{2}\right]-\mathbb{E}\left(\log \left(P_{j, t}(i)\right)-\bar{P}_{t-1}\right)^{2} } \\
&= {\left[\alpha_{j} \operatorname{Var}\left(P_{j, t-1}(i)\right)+\left(1-\alpha_{j}\right)\left(\log \left(\tilde{P}_{j, t}(i)\right)-\bar{P}_{t-1}\right)^{2}\right]-\left(\Delta \bar{P}_{t}\right)^{2}, }
\end{aligned}
$$


by defining $\Delta \bar{P}_{t}=\bar{P}_{t}-\bar{P}_{t-1}=\log \left(P_{j, t}(i)\right)-\bar{P}_{t-1}$.

We note that

$$
\begin{aligned}
\Delta \bar{P}_{t} & =\left[\alpha_{j} \bar{P}_{t-1}+\left(1-\alpha_{j}\right) \log \left(\tilde{P}_{t}(i)\right)\right]-\bar{P}_{t-1} \\
& =\left(1-\alpha_{j}\right)\left[\log \left(\tilde{P}_{t}(i)-\bar{P}_{t-1}\right]\right.
\end{aligned}
$$

(34) is written as

$$
\begin{aligned}
\operatorname{Var}\left(\hat{P}_{j, t}(i)\right) & =\alpha_{j} \operatorname{Var}\left(\hat{P}_{j, t-1}(i)\right)+\frac{1}{1-\alpha_{j}}\left(\Delta \bar{P}_{t}\right)^{2}-\left(\Delta \bar{P}_{t}\right)^{2} \\
& =\alpha_{j} \operatorname{Var}\left(\hat{P}_{j, t-1}(i)\right)+\frac{\alpha_{j}}{1-\alpha_{j}}\left(\Delta \bar{P}_{t}\right)^{2}
\end{aligned}
$$

We note that

$$
\bar{P}_{t}=\log \left(P_{j, t}\right)+o\left(\|\xi\|^{3}\right)
$$

which implies

$$
\Delta \bar{P}_{t}=\pi_{j, t}+o\left(\|\xi\|^{3}\right) \text {. }
$$

Thus, we obtain

$$
\operatorname{Var}\left(\hat{P}_{j, t}(i)\right)=\alpha_{j} \operatorname{Var}\left(\hat{P}_{j, t-1}(i)\right)+\frac{\alpha_{j}}{1-\alpha_{j}}\left(\pi_{j, t}\right)^{2}+o\left(\|\xi\|^{3}\right)
$$

By backward iteration, we have

$$
\begin{aligned}
\operatorname{Var}\left(\hat{P}_{j, t}(i)\right) & =\alpha_{j}^{t+1} \operatorname{Var}\left(P_{j,-1}(i)\right)+\sum_{s=0}^{t} \alpha_{j}^{t-s} \frac{\alpha_{j}}{1-\alpha_{j}}\left(\pi_{j, s}\right)^{2}+o\left(\|\xi\|^{3}\right) \\
& =\sum_{s=0}^{t} \alpha_{j}^{t-s} \frac{\alpha_{j}}{1-\alpha_{j}}\left(\pi_{j, s}\right)^{2}+t . i \cdot p \cdot+o\left(\|\xi\|^{3}\right) .
\end{aligned}
$$

$\alpha_{j}^{t+1} \operatorname{Var}\left(P_{j,-1}(i)\right)$ is independent of the policy conducted from $t \geq 0$.

We take the discounted value over time. We obtain

$$
\sum_{t=0}^{\infty} \beta^{t} \operatorname{Var}\left(\hat{P}_{j, t}(i)\right)=\frac{\alpha_{j}}{\left(1-\alpha_{j}\right)\left(1-\alpha_{j} \beta\right)} \sum_{t=0}^{\infty} \beta^{t} \pi_{j, t}^{2}+t . i . p .+o\left(\|\xi\|^{3}\right) .
$$


By substituting (35) into (33),

$$
\sum_{t=0}^{\infty} \beta^{t} \operatorname{Var}\left(\hat{Y}_{j, t}(i)\right)=\sigma^{2} \frac{\alpha_{j}}{\left(1-\alpha_{j}\right)\left(1-\alpha_{j} \beta\right)} \sum_{t=0}^{\infty} \beta^{t} \pi_{j, t}^{2}+t . i \cdot p .+o\left(\|\xi\|^{3}\right) .
$$

We take the discounted sum of (32) with (36)

$$
\begin{aligned}
& \sum_{t=0}^{\infty} \beta^{t} \sum_{j=1}^{J} n_{j} w_{t}^{j}=-\frac{1}{2} U_{C} \bar{C} \sum_{t=0}^{\infty} \beta^{t}\left[\begin{array}{l}
(\rho+\eta)\left(\hat{Y}_{t}-\tilde{Y}_{t}\right)^{2}+(1+\eta) \sum_{j=1}^{J} n_{j}\left(\hat{P}_{j, t}^{R}-\tilde{P}_{j, t}^{R}\right)^{2} \\
+\left(\eta+\frac{1}{\sigma}\right) \sum_{j=1}^{J} n_{j} \operatorname{Var}\left(\hat{Y}_{j, t}(i)\right)
\end{array}\right] \\
& + \text { t.i.p. }+o\left(\|\xi\|^{3}\right) \\
& =-\frac{1}{2} U_{C} \bar{C} \sum_{t=0}^{\infty} \beta^{t}\left\{(\rho+\eta)\left(\hat{Y}_{t}-\tilde{Y}_{t}\right)^{2}+(1+\eta) \sum_{j=1}^{J} n_{j}\left(\hat{P}_{j, t}^{R}-\tilde{P}_{j, t}^{R}\right)^{2}\right\} \\
& -\frac{1}{2} U_{C} \bar{C}\left(\eta+\frac{1}{\sigma}\right) \sum_{j=1}^{J} n_{j} \sum_{t=0}^{\infty} \beta^{t} \operatorname{Var}\left(\hat{Y}_{j, t}(i)\right)+t . i \cdot p .+o\left(\|\xi\|^{3}\right) \\
& =-\frac{1}{2} U_{C} \bar{C} \sum_{t=0}^{\infty} \beta^{t}\left\{(\rho+\eta)\left(\hat{Y}_{t}-\tilde{Y}_{t}\right)^{2}+(1+\eta) \sum_{j=1}^{J} n_{j}\left(\hat{P}_{j, t}^{R}-\tilde{P}_{j, t}^{R}\right)^{2}\right\} \\
& -\frac{1}{2} U_{C} \bar{C}\left(\eta+\frac{1}{\sigma}\right) \sum_{j=1}^{J} n_{j}\left\{\sigma^{2} \frac{\alpha_{j}}{\left(1-\alpha_{j}\right)\left(1-\alpha_{j} \beta\right)} \sum_{t=0}^{\infty} \beta^{t} \pi_{j, t}^{2}\right\}+t . i \cdot p .+o\left(\|\xi\|^{3}\right) \\
& =-\frac{1}{2} U_{C} \bar{C} \sum_{t=0}^{\infty} \beta^{t}\left[\begin{array}{l}
(\rho+\eta)\left(\hat{Y}_{t}-\tilde{Y}_{t}\right)^{2}+(1+\eta) \sum_{j=1}^{J} n_{j}\left(\hat{P}_{j, t}^{R}-\tilde{P}_{j, t}^{R}\right)^{2} \\
+\left(\eta+\frac{1}{\sigma}\right) \sigma^{2} \sum_{j=1}^{J} n_{j} \frac{\alpha_{j}}{\left(1-\alpha_{j}\right)\left(1-\alpha_{j} \beta\right)} \pi_{j, t}^{2}
\end{array}\right] \\
& +t . i . p .+o\left(\|\xi\|^{3}\right) \\
& =-\frac{1}{2} U_{C} \bar{C} \sum_{t=0}^{\infty} \beta^{t}\left[\begin{array}{l}
(\rho+\eta)\left(\hat{Y}_{t}-\tilde{Y}_{t}\right)^{2}+(1+\eta) \sum_{j=1}^{J} n_{j}\left(\hat{P}_{j, t}^{R}-\tilde{P}_{j, t}^{R}\right)^{2} \\
+(1+\eta \sigma) \sigma \sum_{j=1}^{J} n_{j} \frac{\alpha_{j}}{\left(1-\alpha_{j}\right)\left(1-\alpha_{j} \beta\right)} \pi_{j, t}^{2}
\end{array}\right] \\
& + \text { t.i.p. }+o\left(\|\xi\|^{3}\right) \text {. }
\end{aligned}
$$

By taking expectation on it, we obtain

$$
\begin{aligned}
\mathbb{E}_{0} \sum_{t=0}^{\infty} \beta^{t} \sum_{j=1}^{J} n_{j} w_{t}^{j}= & -\frac{1}{2} U_{C} \bar{C} \mathbb{E}_{0} \sum_{t=0}^{\infty} \beta^{t}\left[\begin{array}{l}
(\rho+\eta)\left(\hat{Y}_{t}-\tilde{Y}_{t}\right)^{2}+(1+\eta) \sum_{j=1}^{J} n_{j}\left(\hat{P}_{j, t}^{R}-\tilde{P}_{j, t}^{R}\right)^{2} \\
+(1+\eta \sigma) \sigma \sum_{j=1}^{J} n_{j} \frac{\alpha_{j}}{\left(1-\alpha_{j}\right)\left(1-\alpha_{j} \beta\right)} \pi_{j, t}^{2}
\end{array}\right] \\
& + \text { t.i.p. }+o\left(\|\xi\|^{3}\right) .
\end{aligned}
$$

Thus, we derive 


$$
L_{t}=(\rho+\eta)\left(\hat{Y}_{t}-\tilde{Y}_{t}\right)^{2}+(1+\eta) \sum_{j=1}^{J} n_{j}\left(\hat{P}_{j, t}^{R}-\tilde{P}_{j, t}^{R}\right)^{2}+(1+\eta \sigma) \sigma \sum_{j=1}^{J} n_{j} \frac{\alpha_{j}}{\left(1-\alpha_{j}\right)\left(1-\alpha_{j} \beta\right)} \pi_{j, t}^{2}
$$

C Numerical Results when $\phi^{A}=0.84$ and $\sigma^{A}=0.0084$

We obtain the OPI inflation and the implied nominal interest rates when $\phi^{A}=0.84$ and $\sigma^{A}=0.0084$. We take these values from Bae (2013).

[Table 7] Optimal weights $\left(\phi^{A}=0.84\right)$

\begin{tabular}{llccc}
\hline & CPI expenditure categories & $n_{j}(\%)$ & $\alpha_{j}$ & $\delta_{j}^{*}(\%)$ \\
\hline 1 & Food and non-alcoholic beverages & 14.15 & 0.1943 & 2.95 \\
2 & Alcoholic beverages and tobacco & 1.30 & 0.0435 & 0.04 \\
3 & Clothing and footwear & 6.44 & 0.7234 & 15.03 \\
4 & Housing, water, electricity, and other fuels & 10.13 & 0.6180 & 13.42 \\
5 & Furnishings, household equipment, and routine household & 3.73 & 0.4679 & 2.52 \\
& maintenance & & & \\
6 & Health & 6.36 & 0.4690 & 4.36 \\
7 & Transport & 12.28 & 0.3613 & 5.15 \\
8 & Communication & 6.41 & 0.0583 & 0.45 \\
9 & Recreation and culture & 5.51 & 0.2497 & 1.46 \\
10 & Education & 11.77 & 0.5578 & 10.84 \\
11 & Restaurants and hotels & 13.27 & 0.7720 & 38.77 \\
12 & Miscellaneous goods and services & 8.65 & 0.4231 & 5.01 \\
\hline
\end{tabular}

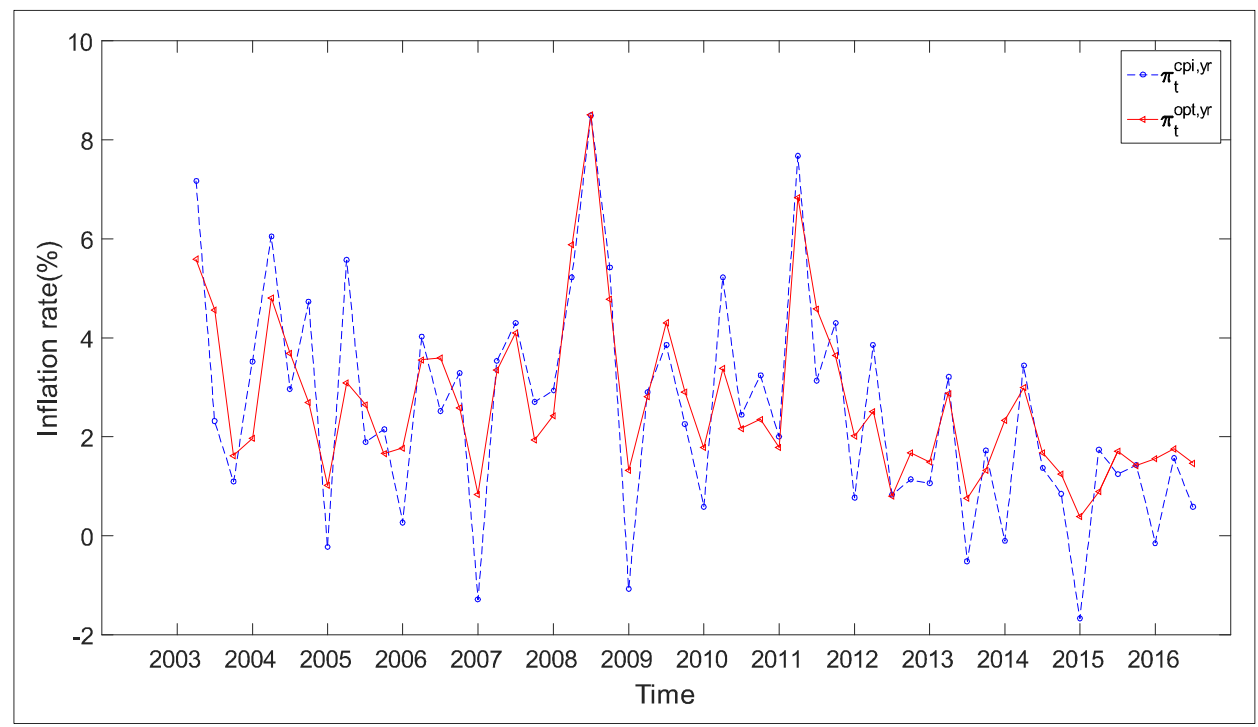


[Table 8] Volatility and persistence of inflation rates $\left(\phi^{A}=0.84\right)$

\begin{tabular}{lccc}
\hline Inflation rate index & $\pi^{\text {opt,yr}}$ & $\pi^{\text {cpi,yr }}$ & $\pi^{\text {core, } y r}$ \\
\hline Standard deviation & 1.6211 & 2.2215 & 1.5841 \\
Autocorrelation & 0.4107 & 0.0626 & 0.2756 \\
\hline
\end{tabular}

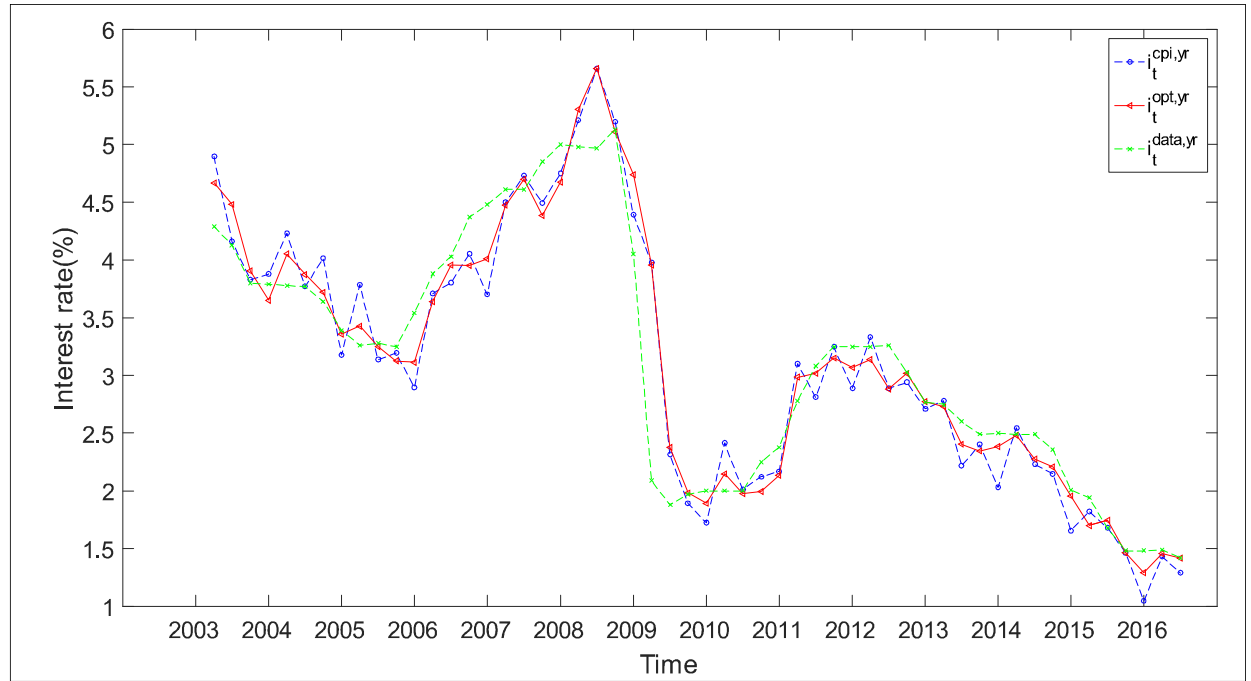

[Table 9] Volatility and persistence of nominal interest rates $\left(\phi^{A}=0.84\right)$

\begin{tabular}{lccc}
\hline Interest rates & $i^{\text {opt }, y r}$ & $i^{\text {cpi,yr }}$ & $i^{\text {core }, y r}$ \\
\hline Standard deviation & 1.1094 & 1.1399 & 1.1012 \\
Autocorrelation & 0.9031 & 0.8610 & 0.8886 \\
\hline
\end{tabular}

[Table 10] Correlation between the model implied and the actual interest rates $\left(\phi^{A}=0.84\right)$

\begin{tabular}{lcccc}
\hline Correlation of $i^{\text {data, } y r}$ & with & $i^{\text {opt }, y r}$ & $i^{\text {cpi,yr }}$ & $i^{\text {core }, y r}$ \\
\hline Correlation & 0.9460 & 0.9365 & 0.9305 \\
\hline
\end{tabular}




\section{Figures with Core Inflation}

[Figure 6] Inflation rates

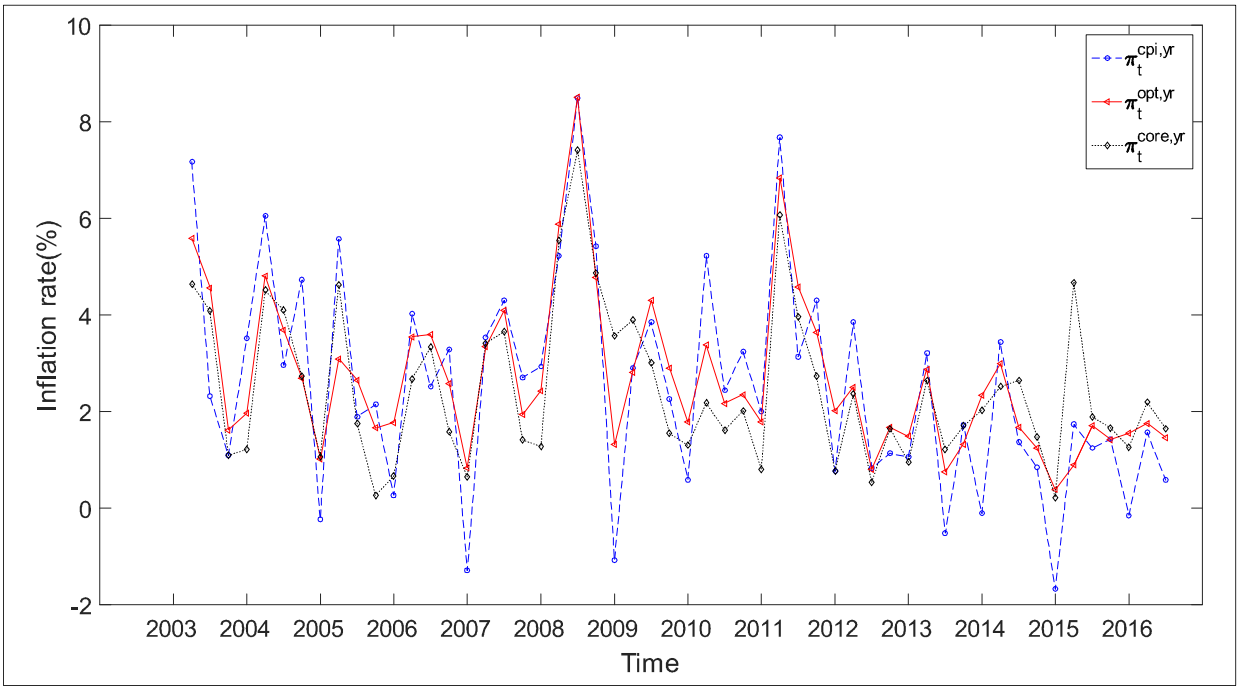

[Table 11] Volatility and persistence of inflation rates

\begin{tabular}{lccc}
\hline Inflation rate index & $\pi^{\text {opt,yr}}$ & $\pi^{\text {cpi,yr }}$ & $\pi^{\text {core }, y r}$ \\
\hline Standard deviation & 1.6419 & 2.2215 & 1.5841 \\
Autocorrelation & 0.3780 & 0.0626 & 0.2756 \\
\hline
\end{tabular}

[Figure 7] Nominal interest rates

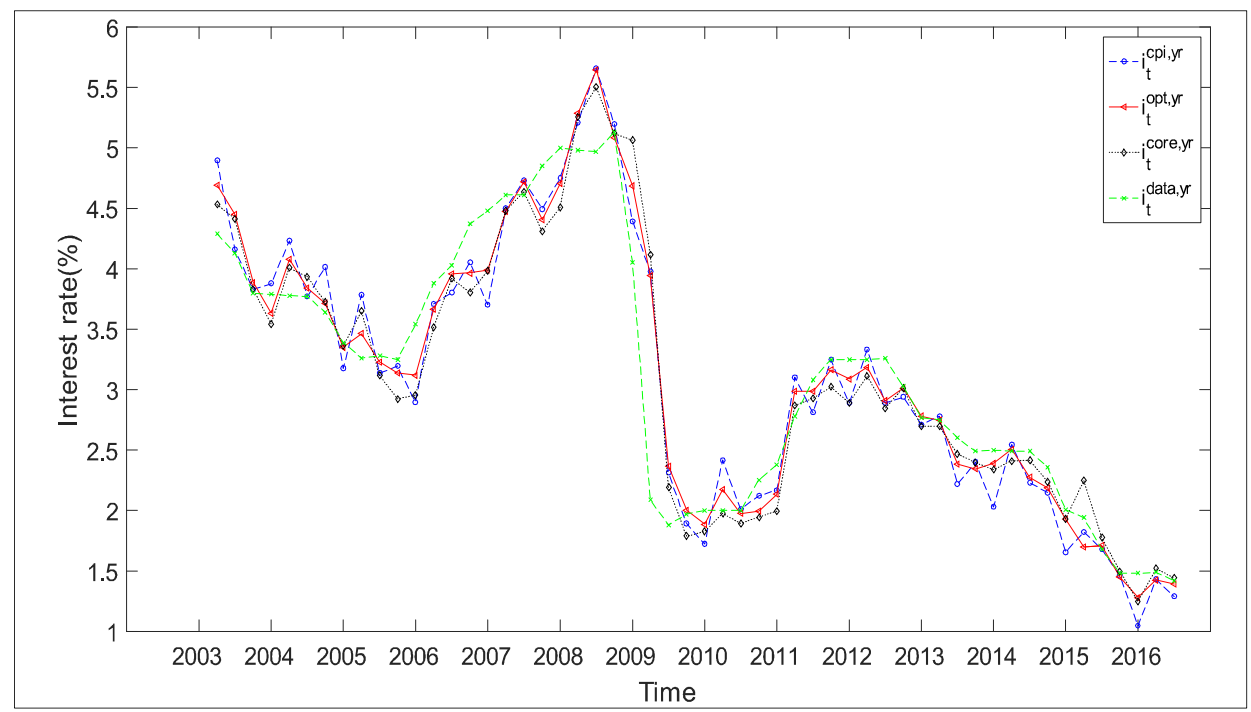


[Table 12] Volatility and persistence of nominal interest rates

\begin{tabular}{lccc}
\hline Interest rates & $i^{\text {opt }, y r}$ & $i^{c p i, y r}$ & $i^{\text {core } y r}$ \\
\hline Standard deviation & 1.1105 & 1.1399 & 1.1012 \\
Autocorrelation & 0.9015 & 0.8610 & 0.8886 \\
\hline
\end{tabular}

[Table 13] Correlation between the model implied and the actual interest rates

\begin{tabular}{|c|c|c|c|}
\hline Correlation of $i^{\text {data,yr}}$ with & $i^{o p t, y r}$ & $i^{c p i, y r}$ & $i^{\text {core }, y r}$ \\
\hline Correlation & 0.9475 & 0.9365 & 0.9305 \\
\hline
\end{tabular}

\section{E Extension: A Small Open Economy in the Limiting Case}

In this section, we consider a small open economy extension to our multisector model. The world economy consists of a continuum of small open economies (indexed by $f \in[0,1]$ ), one of which is the home country.

We assume that each country has a representative household. The aggregate consumption index is given as

$$
C_{t} \equiv\left[(1-\xi)^{\frac{1}{\eta^{F}}}\left(C_{t}^{H}\right)^{\frac{\eta^{F}-1}{\eta^{F}}}+\xi^{\frac{1}{\eta^{F}}}\left(C_{t}^{F}\right)^{\frac{\eta^{F}-1}{\eta^{F}}}\right]^{\frac{\eta^{F}}{\eta^{F}-1}}
$$

where $C_{t}^{H}$ and $C_{t}^{F}$ are respectively a composite of goods produced in the home and foreign countries, $\xi$ measures the degree of openness, and $\eta^{F}$ measures the substitutability between domestic and foreign goods. The CPI, the price index of domestic goods, and the sectoral price index are respectively given as

$$
\begin{aligned}
& P_{t}=\left[(1-\xi)\left(P_{t}^{H}\right)^{1-\eta^{F}}+\xi\left(P_{t}^{F}\right)^{1-\eta^{F}}\right]^{\frac{1}{1-\eta^{F}}}, \\
& P_{t}^{H}=\prod_{j=1}^{J}\left(P_{j, t}^{H}\right)^{n_{j}}, \text { and } \\
& P_{j, t}^{H}=\left[\left(\frac{1}{n_{j}}\right) \int_{\mathcal{I}_{j}} P_{j, t}^{H}(i)^{1-\sigma} d i\right]^{\frac{1}{1-\sigma}} .
\end{aligned}
$$

The price index of foreign goods is given as

$$
P_{t}^{F}=\left[\int_{0}^{1}\left(P_{t}^{f}\right)^{1-\gamma^{F}} d f\right]^{\frac{1}{1-\gamma^{F}}}
$$


where $P_{t}^{f}$ is the price index for goods imported from country $f$, and $\gamma^{F}$ measures the substitutability between goods produced in different countries.

The demand for domestic and foreign goods are then given as

$$
\begin{aligned}
& C_{t}^{H}=(1-\xi)\left(\frac{P_{t}^{H}}{P_{t}}\right)^{-\eta^{F}} C_{t}, \\
& C_{j, t}^{H}=n_{j}\left(\frac{P_{j, t}^{H}}{P_{t}^{H}}\right)^{-1} C_{t}^{H}, \\
& C_{j, t}^{H}(i)=\left(\frac{P_{j, t}^{H}(i)}{P_{j, t}^{H}}\right)^{-\sigma}\left(\frac{P_{j, t}^{H}}{P_{t}^{H}}\right)^{-1} C_{t}^{H}, \\
& C_{t}^{F}=\xi\left(\frac{P_{t}^{F}}{P_{t}}\right)^{-\eta^{F}} C_{t}, \text { and } \\
& C_{t}^{f}=\left(\frac{P_{t}^{f}}{P_{t}^{F}}\right)^{-\gamma^{F}} C_{t}^{F} .
\end{aligned}
$$

The first-order optimality conditions are the same:

$$
\begin{aligned}
& N_{j, t}(i)^{\eta} C_{t}^{\rho}=W_{j, t}(i) / P_{t} \text { and } \\
& R_{t}^{-1}=\beta \mathbb{E}_{t}\left[\left(C_{t}^{\rho} / C_{t+1}^{\rho}\right)\left(P_{t} / P_{t+1}\right)\right],
\end{aligned}
$$

where $\mathbb{E}_{t} Q_{t, t+1}=R_{t}^{-1}$.

We introduce several definitions. The bilateral terms of trade between home country and country $f$ is given as

$$
S_{t}^{f} \equiv \frac{P_{t}^{f}}{P_{t}^{H}}
$$

and the effective terms of trade is

$$
S_{t}=\frac{P_{t}^{F}}{P_{t}^{H}}=\left[\int_{0}^{1}\left(S_{t}^{f}\right)^{1-\gamma^{F}}\right]^{\frac{1}{1-\gamma^{F}}}
$$

Let $\varepsilon_{t}^{f}$ be the nominal exchange rate between country $f$ and home country, denominated by home country's currency, and $P_{t}^{f f}$ be the price of country $f$ goods expressed in country $f$ 's currency. Assuming the law of one price, one 
obtains $P_{t}^{f}=\varepsilon_{t}^{f} P_{t}^{f f}$. We also define the bilateral real exchange rate with country $f$ as

$$
Q_{t}^{f} \equiv \frac{P_{t}^{f}}{P_{t}},
$$

which is the ratio between the CPIs.

Under complete markets, the representative household in country $f$ also has the first-order condition:

$$
\mathbb{E}_{t} Q_{t, t+1}=\beta \mathbb{E}_{t}\left[\left(\left(C_{t}^{f}\right)^{\rho} /\left(C_{t+1}^{f}\right)^{\rho}\right)\left(P_{t}^{f} / P_{t+1}^{f}\right)\right]
$$

Combining (38) with (39) and integrating over $f$ give the log-linearized international risk sharing condition

$$
\hat{C}_{t}=\hat{C}_{t}^{*}+\frac{1}{\rho} \hat{Q}_{t}
$$

where $\hat{C}_{t}^{*} \equiv \int_{0}^{1} \hat{C}_{t}^{f} d f$ and $\hat{Q}_{t}=\int_{0}^{1} \hat{Q}_{t}^{f} d f$.

The goods market clearing condition for each type of product is

$$
\begin{aligned}
Y_{j, t}(i) & =C_{j, t}^{H}(i)+X_{j, t}(i) \\
& =\left(\frac{P_{j, t}^{H}(i)}{P_{j, t}^{H}}\right)^{-\sigma}\left(\frac{P_{j, t}^{H}}{P_{t}^{H}}\right)^{-1}\left[(1-\xi)\left(\frac{P_{t}^{H}}{P_{t}}\right)^{-\eta^{F}} C_{t}+\xi S_{t}^{\eta^{F}} Y_{t}^{*}\right] .
\end{aligned}
$$

Aggregation implies that

$$
\begin{aligned}
& Y_{j, t}=\left(\frac{P_{j, t}^{H}}{P_{t}^{H}}\right)^{-1}\left[(1-\xi)\left(\frac{P_{t}^{H}}{P_{t}}\right)^{-\eta^{F}} C_{t}+\xi S_{t}^{\eta^{F}} Y_{t}^{*}\right] \text { and } \\
& Y_{t}=(1-\xi)\left(\frac{P_{t}^{H}}{P_{t}}\right)^{-\eta^{F}} C_{t}+\xi S_{t}^{\eta^{F}} Y_{t}^{*}
\end{aligned}
$$

As in Clarida et al. (2001) and Gali and Monacelli (2005), we consider the case of $\rho=\eta^{F}=\gamma^{F}=1 .^{21}$ In this case, Equation (40), (41), and (42) imply

\footnotetext{
${ }^{21}$ This equation implies that $P_{t}=\left(P_{t}^{H}\right)^{1-\xi}\left(P_{t}^{F}\right)^{\xi}$.
} 


$$
\begin{aligned}
& \hat{Y}_{j, t}=-\hat{P}_{j, t}^{R^{H}}+\xi \hat{S}_{t}+\hat{C}_{t}, \\
& \hat{Y}_{t}=\xi \hat{S}_{t}+\hat{C}_{t}=\hat{Y}_{t}^{*}+\hat{S}_{t}, \text { and } \\
& \hat{C}_{t}=\hat{C}_{t}^{*}+(1-\xi)\left(\hat{Y}_{t}-\hat{Y}_{t}^{*}\right)=\xi \hat{Y}_{t}^{*}+(1-\xi) \hat{Y}_{t} .
\end{aligned}
$$

Following the same procedures in Gali and Monacelli (2005), particularly using the relationships above to write the dynamic IS curve and Phillips curve in terms of domestic output and inflation, the equilibrium conditions are isomorphic to those in the closed economy. Moreover, the central bank's loss function can be written as

$$
\mathcal{L}=\frac{1-\xi}{2} \mathbb{E}_{0} \sum_{t=0}^{\infty} \beta^{t} L_{t}
$$

Therefore, the loss function is the same as its closed-economy counterpart up to the multiplicative term $(1-\xi)$, which depends on the extent of openness. This result implies that a simple, small open-economy extension does not change the main results obtained from the closed economy model. 


\section{References}

Aoki, Kosuke (2001), “Optimal Monetary Policy Responses to Relative-price Changes," Journal of Monetary Economics, 48(1), 55-80.

Barsky, R., C. House and M. Kimball (2007) "Sticky Price Models and Durable Goods," American Economic Review, 97(3), 984-998

Bhattarai, Saroj, Jae Won Lee, and Woong Yong Park (2015), “Optimal Monetary Policy in a Currency Union with Interest Rate Spreads," Journal of International Economics, 96(2), 375-397.

Benigno, Pierpaolo (2004), “Optimal Monetary Policy in a Currency Area," Journal of International Economics, 63, 293-320.

Bils, Mark and Peter J. Klenow (2004), "Some Evidence on the Importance of Sticky Prices," Journal of Political Economy, University of Chicago Press, 112(5), 947-985.

Bouakez, Hafedh, Emanuela Cardia, and Francisco J. Ruge-Murcia (2009), "The Transmission of Monetary Policy in a Multisector Economy," International Economic Review, 50(4), 1243-1266.

Calvo, Guillermo A. (1983), "Staggered Prices in a Utility-maximizing Framework," Journal of Monetary Economics, 12(3), 383-398.

Carvalho, Carlos, Niels Arne Dam, and Jae Won Lee (2020), “The Cross-Sectional Distribution of Price Stickiness Implied by Aggregate Data," forthcoming in Review of Economics and Statistics.

Carvalho, Carlos, Jae Won Lee, and Woong Yong Park (2020), "Sectoral Price Facts in a Sticky-price Model," forthcoming in American Economic Journal: Macroeconomics.

Carvalho, Carlos, and Felipe Schwartzman (2008), "Heterogeneous Price Setting Behavior and Monetary Non-neutrality: Some General Results," Unpublished working paper.

Carlstrom, C., T. Fuerst and F. Ghironi (2006), "Does It Matter (for Equilibrium Determinacy) What Price Index the Central Bank Targets?" Journal Economic Theory, 128, 214-231.

Chung, Jaesik, Yongseung Jung, and Doo Yong Yang (2007), “Optimal Monetary Policy in a Small Open Economy: The Case of Korea," Journal of Asian Economics, 18, 125-143.

Clarida, Richard, Jordi Gali, and Mark Gertler (2001), "Optimal Monetary Policy in Open versus Closed Economies: An Integrated Approach," American Economic Review, 91 (2), 248-252.

Eusepi, Stefano, Bart Hobijn, and Andrea Tambalotti (2011), "CONDI: A Cost-OfNominal-Distortions Index," American Economic Journal: Macroeconomics, 3(3), 53-91.

Gali, Jordi and Monacelli, Tommaso (2005), "Monetary Policy and Exchange Rate Volatility in a Small Open Economy," Review of Economic Studies, 72(3), 707-734.

Kim, Bae-Geun, and Byung Kwun Ahn (2008), "An Assessment of the New Keynesian Philips Curve in the Korean Economy,” Economic Analysis, 14(3), The Bank of Korea Economic Research Institute.

Kim, Soyoung, and Yung Chul Park (2006), "Inflation Targeting in Korea: A Model of Success?” BIS papers No. 31, 140-164. Bank for International Settlements. 
Kim, Tae Bong (2014), "Analysis on Korean Economy with an Estimated DSGE Model after 2000,” KDI Journal of Economic Policy, 36(2), Korea Development Institute.

Lee, Jae Won (2014), "Monetary Policy with Heterogeneous Households and Imperfect Risk-Sharing," Review of Economic Dynamics, 17(3), 505-522.

(2016), "Heterogeneous Households, Real Rigidity, and Estimated Duration of Price Contracts in a Sticky Price DSGE Model," Unpublished working paper.

Lee, Jae Won, and Woong Yong Park (2016), "Cross-Sectional Distribution of Price Stickiness and Inflation Stability," Unpublished working paper.

Lee, Jae Won, and Yeji Sung (2016), "Optimal Index Versus Simple Index for Monetary Policy,” Unpublished working paper.

Mankiw, N. Gregory, and Ricardo Reis (2003), "What Measure of Inflation Should a Central Bank Target?” Journal of the European Economic Association, MIT Press, 1(5), 1058-1086, 09.

Nakamura, Emi, and Jon Steinsson (2008), "Five Facts About Prices: A Reevaluation of Menu Cost Models," Quarterly Journal of Economics, 123(4), 1415-1464.

Obstfeld, M., K. Rogoff (1998), Risk and Exchange Rates. NBER Working Paper No.6694.

(2000), "New Directions for Stochastic Open Economy Models," Journal of International Economics, 60, 117-153.

Woodford, M. (2003), Interest and Prices: Foundations of a Theory of Monetary Policy, Princeton NJ: Princeton University Press.

Yun, T. (1996), "Nominal Price Rigidity, Money Supply Endogeneity, and Business Cycles," Journal of Monetary Economics, 37, 345-370.

Yun, Tack (2005), "Optimal Monetary Policy with Relative Price Distortions," American Economic Review, 95(1), 89-109. 